\title{
Headspace single drop microextraction versus dispersive liquid-liquid microextraction using magnetic ionic liquid extraction solvents
}

\author{
Jiwoo An, Kira L. Rahn, and Jared L. Anderson ${ }^{*}$
}

\begin{abstract}
A headspace single drop microextraction (HS-SDME) method and a dispersive liquidliquid microextraction (DLLME) method were developed using two tetrachloromanganate ([ $\left.\mathrm{MnCl}_{4}{ }^{2-}\right]$ )-based magnetic ionic liquids (MIL) as extraction solvents for the determination of twelve aromatic compounds, including four polyaromatic hydrocarbons, by reversed phase highperformance liquid chromatography (HPLC). The analytical performance of the developed HSSDME method was compared to the DLLME approach employing the same MILs. In the HSSDME approach, the magnetic field generated by the magnet was exploited to suspend the MIL solvent from the tip of a rod magnet. The utilization of MILs in HS-SDME resulted in a highly stable microdroplet under elevated temperatures and long extraction times, overcoming a common challenge encountered in traditional SDME approaches of droplet instability. The low UV absorbance of the $\left[\mathrm{MnCl}_{4}{ }^{2-}\right]$-based MILs permitted direct analysis of the analyte enriched extraction solvent by HPLC. In HS-SDME, the effects of ionic strength of the sample solution, temperature of the extraction system, extraction time, stir rate, and headspace volume on extraction efficiencies were examined. Coefficients of determination $\left(\mathrm{R}^{2}\right)$ ranged from 0.994 to 0.999 and limits of detection (LODs) varied from 0.04 to $1.0 \mu \mathrm{g} \mathrm{L}^{-1}$ with relative recoveries from lake water ranging from $70.2 \%$ to $109.6 \%$. For the DLLME method, parameters including disperser solvent type and volume, ionic strength of the sample solution, mass of extraction solvent, and extraction time were studied and optimized. Coefficients of determination for the DLLME method varied from 0.997 to 0.999 with LODs ranging from 0.05 to $1.0 \mu \mathrm{g} \mathrm{L}^{-1}$. Relative recoveries from lake water samples ranged from $68.7 \%$ to $104.5 \%$. Overall, the DLLME approach permitted faster extraction times and higher enrichment factors for analytes with low vapor pressure whereas the HS-SDME approach exhibited better extraction efficiencies for analytes with relatively higher vapor pressure.
\end{abstract}

Keywords: Magnetic ionic liquids; Headspace single drop microextraction; Dispersive liquidliquid microextraction; High performance liquid chromatography 


\section{Introduction}

Sample pretreatment and preconcentration are widely recognized as bottlenecks in the sample preparation of analytes within complex matrices [1]. Many extraction techniques have been developed in the past several decades to preconcentrate target analytes. However, the need for faster, cost-effective, and convenient methods which are capable of high-throughput analysis are still in demand. Traditional sample preparation methods such as liquid-liquid extraction (LLE) often involve tedious and labor intensive procedures as well as require large volumes of toxic organic solvents [2, 3]. Miniaturized LLE techniques, often referred to as liquid-phase microextraction (LPME), have been introduced in efforts to overcome the disadvantages of conventional sample preparation systems [4-6].

Dispersive liquid-liquid microextraction (DLLME) and single drop microextraction (SDME) are two widely used microextraction techniques. DLLME was first introduced by Rezaee and co-workers in 2006 as a simple extraction method that allows preconcentration of organic compounds by dispersing a water-immiscible organic solvent [7]. Once a mixture of disperser solvent and extraction solvent is added to an aqueous sample, a cloudy solution is formed. The high surface area of the extraction solvent facilitates rapid extraction of analytes [2, 7]. SDME, introduced in 1996 by Liu and Dasgupta, utilizes a micro-liter volume of a single organic droplet to preconcentrate analytes [8, 9]. SDME can be employed in the directimmersion (DI) or headspace (HS) modes, depending largely on the types of analytes being extracted and the complexity of the matrix [10]. In DI-SDME, the extraction solvent droplet is directly immersed in the sample solution, enabling extraction of non-volatile compounds. On the other hand, HS-SDME is useful for the extraction of volatile or semi-volatile compounds from 
complex sample matrices as the analytes are extracted from the headspace above the sample solution $[5,11]$.

In an effort to investigate alternative solvent systems for DLLME and SDME, ionic liquids (ILs) have enjoyed increasing popularity due to their unique properties [5, 12-14]. The chemical structures of IL cations and anions can be tailored to impact a number of unique physicochemical properties including low or negligible vapor pressure at room temperature, high thermal stability, and variable viscosity. One of the more appealing characteristics of ILs in analytical chemistry is that they can be designed for specific applications [15]. Within the past decade, ILs have been successfully applied to DLLME and SDME methods for the analysis of a wide range of analytes including polycyclic aromatic hydrocarbons (PAHs) [12, 16, 17], insecticides [14], pesticides [18, 19], phenols [20, 21], and metals [22-24]. Magnetic ionic liquids (MILs) are a subclass of ILs that exhibit paramagnetic behavior due to the incorporation of either paramagnetic cations or anions in their structures, allowing them to be readily manipulated through the use of an applied magnetic field. MILs have received an increasing amount of attention as solvent systems in various of analytical techniques [25]. When used as extraction solvents in microextraction techniques, MILs provide important advantages that conventional ILs cannot offer. For example, the centrifugation step in DLLME, which is typically required to achieve phase separation between the aqueous sample solution and the extraction phase, can be eliminated by simply retrieving the dispersed MIL microdroplets through the use of a magnet $[26,27]$. The elimination of the centrifugation step greatly reduces the analysis time and opens up the prospects of creating entirely automated methods. In HSSDME, droplet stability is an inevitable issue due to a small surface area of the microsyringe needle tip which holds the microdroplet. In addition, organic solvents with high boiling points 
may still possess some volatility, especially at high extraction temperatures, leading to loss of extraction solvent volume over long extraction times [11]. Therefore, applying MILs in HSSDME may provide advantages leading to improvement over existing methods.

There are few reported studies using MILs as extraction solvents [26-31]. The majority of the studies were performed with MILs containing the $\mathrm{Fe}(\mathrm{III})$ anion $\left(\left[\mathrm{FeCl}_{4}^{-}\right]\right)$, which is susceptible to hydrolysis in aqueous solutions and exhibits high absorption in the ultraviolet (UV) region [32-35]. These characteristics not only present difficulties in designing simple extraction procedures, but they also limit the choice of detection method. For example, high UV absorbance may interfere with analyte detection when high-performance liquid chromatography (HPLC) coupled to UV detection is used. Recently, MILs containing the tetrachloromanganate anion $\left(\left[\mathrm{MnCl}_{4}{ }^{2-}\right]\right)$ were utilized as extraction solvents in DLLME coupled to HPLC, taking advantage of the low UV absorbance exhibited by this anion [27]. However, the $\left[\mathrm{MnCl}_{4}{ }^{2-}\right]$-based MILs have not been well studied and have not been applied in other extraction systems. Thus, further studies into the use of MILs in microextraction techniques is important in order to improve existing methods.

In this study, we present for the first time a HS-SDME method which utilizes two $\left[\mathrm{MnCl}_{4}{ }^{2-}\right]$-based MILs, namely, trihexyl(tetradecyl)phosphonium tetrachloromanganate $\left(\left[\mathrm{P}_{6,6,6,14}{ }^{+}\right]_{2}\left[\mathrm{MnCl}_{4}{ }^{2-}\right]\right)$ and aliquat tetrachloromanganate ([Aliquat $\left.\left.{ }^{+}\right]_{2}\left[\mathrm{MnCl}_{4}{ }^{2-}\right]\right)$ coupled to HPLC. The two cations have been previously shown to exhibit different extraction efficiencies despite small differences in their chemical structure when used in DLLME [27]. They have never been explored in any SDME platform. The $\left[\mathrm{MnCl}_{4}{ }^{2-}\right]$-based MILs exhibit no sign of hydrolysis in aqueous solution unlike the $\left[\mathrm{FeCl}_{4}{ }^{-}\right]$-based MILs, enabling sampling without $\mathrm{pH}$ adjustment. In addition, the low UV absorbance of the $\left[\mathrm{MnCl}_{4}{ }^{2-}\right]$-based MILs permits direct analysis of the 
extraction solvent by HPLC-UV. Similar MILs have also been applied in studies employing high ionic strength solutions, demonstrating their stability in the presence of salts $[26,27,30]$. When MILs are applied as extraction solvents in HS-SDME, the magnetic force maintains the microdroplet on the magnet support throughout the long extraction time as opposed to the droplet being suspended on the tip of a microsyringe needle. Hence, the use of magnet can significantly increase the droplet stability, overcoming a main disadvantage of traditional HS-SDME. Moreover, the loss of extraction solvent due to evaporation is greatly reduced, as the MILs inherently possess low vapor pressure. Following extraction, the analyte enriched MIL droplet was directly subjected to chromatographic analysis by HPLC. The analytical performance of the HS-SDME method using MILs was compared to a DLLME method in which MILs are used as the dispersive extraction solvent for the determination of various organic compounds. This study highlights the tremendous applicability of MILs in the field of sample preparation.

\section{Experimental}

\subsection{Reagents}

Aliquat 336 (average molecular weight: 442.00) was purchased from Acros Organics (Pittsburgh, PA, USA). Trihexyl(tetradecyl)phosphonium chloride (97.7\%) was purchased from Strem Chemicals (Newburyport, MA, USA). Manganese (II) chloride tetrahydrate (98.0\%) was purchased from Alfa Aesar (Ward Hill, MA, USA). The analytes acetophenone (99.0\%), 2 chloroaniline (>98.0\%), $\alpha, \alpha, \alpha$-6-tetrafluoro-m-toluidine, 4-chlorobutyrophenone, benzophenone (99.0\%), 2-nitronaphthalene (85.0\%), biphenyl (99.5\%), $\alpha, \alpha, \alpha-$-trichlorotoluene (98.0\%), and 1chloro-4-nitrobenzene (99.0\%) were purchased from Sigma Aldrich (St. Louis, MO, USA). The analyte 2-bromo-4-fluorobenzaldehyde (99.0\%) was purchased from Oakwood Products, Inc. 
(West Columbia, SC, USA) and fluorene, phenanthrene, and anthracene with purities greater than $96.0 \%$ were purchased from Supelco (Bellefonte, PA, USA). Sodium chloride was purchased from Fisher Scientific (Fair Lawn, NJ, USA). Acetonitrile, acetone, and methanol $(\geq 99.9 \%)$ were purchased from Sigma Aldrich. Neodymium rod magnets $(0.66 \mathrm{~T})$ were purchased from K\&J Magnetics (Pipersville, PA, USA). Ultrapure water $(18.2 \mathrm{M} \Omega \mathrm{cm}$ ) was produced by a Milli-Q water filtration system (Millipore, Bedford, MA, USA) and was used for the preparation of all solutions.

All analytes and their physical and chemical properties are listed in Table S1. Individual stock solutions were prepared at $5000 \mathrm{mg} \mathrm{L}^{-1}$ in acetonitrile for each analyte, except for the stock solution of anthracene, which was prepared at $1000 \mathrm{mg} \mathrm{L}^{-1}$. A working solution containing all twelve analytes was prepared at $200 \mathrm{mg} \mathrm{L}^{-1}$ in acetonitrile, with the exception of $\alpha, \alpha, \alpha-6-$ tetrafluoro-m-toluidine and biphenyl (100 $\mathrm{mg} \mathrm{L}^{-1}$ and $40 \mathrm{mg} \mathrm{L}^{-1}$, respectively). For consistency, the same working solution was used for the DLLME and HS-SDME methods. Aqueous samples were prepared fresh before each extraction by spiking an appropriate amount of working solution into a $30 \% \mathrm{NaCl}(\mathrm{w} / \mathrm{v})$ aqueous solution.

\subsection{Instrumentation}

An Agilent 1260 Infinity HPLC system (Santa Clara, CA, USA) equipped with a quaternary pump, a manual injector, and a diode array detector was used for chromatographic analysis after DLLME. A Shimadzu LC-20A system (Shimadzu, Japan) consisting of a manual injector, a DGU-20A 3 degasser, two LC-20AT pumps, and a SPD-20 UV/Vis detector was used for separation of analytes after HS-SDME. All separations were performed using a Restek Ultra II C18 column (250 mm x $4.6 \mathrm{~mm}, 5.0 \mathrm{um}$, State College, PA, USA). Ultrapure water and 
acetonitrile were utilized as mobile phases for the separation of all compounds. The gradient separation was started and held at 53\% acetonitrile for 10 minutes, and increased to $80 \%$ over 20 minutes, followed by an immediate increase in acetonitrile to $100 \%$ for 10 minutes. All analytes were detected at $254 \mathrm{~nm}$.

Viscosity measurements of the MILs were performed using a Wells/Brookfield DV1 cone and plate viscometer with a CPA-51Z cone spindle at ambient temperature $\left(21.4^{\circ} \mathrm{C}\right)$. Both MILs were dried in a vacuum oven at $50^{\circ} \mathrm{C}$ for 12 hours prior to the measurement in order to ensure complete removal of water and residual solvents. A sample volume of $0.5 \mathrm{~mL}$ was used for each MIL.

\subsection{Synthesis and characterization of magnetic ionic liquids}

The two magnetic ionic liquids, $\left[\mathrm{P}_{6,6,6,14}{ }^{+}\right]_{2}\left[\mathrm{MnCl}_{4}{ }^{2-}\right]$ and $\left[\text { Aliquat }^{+}\right]_{2}\left[\mathrm{MnCl}_{4}{ }^{2-}\right]$, were synthesized using a previously reported procedure [36, 37] with slight modifications. Briefly, a 0.5 molar equivalent of $\mathrm{MnCl}_{2} \cdot 4 \mathrm{H}_{2} \mathrm{O}$ was added to a methanolic solution of $\left[\mathrm{P}_{6,6,6,14}^{+}\right]\left[\mathrm{Cl}^{-}\right]$. The reaction was stirred at room temperature for $24 \mathrm{~h}$, and the solvent was removed by rotary evaporation. The resulting product was dried overnight in a vacuum oven at $50^{\circ} \mathrm{C}$. Complete characterization of these MILs was reported recently by our group [27]. The $\left[\mathrm{P}_{6,6,6,14}{ }^{+}\right]_{2}\left[\mathrm{MnCl}_{4}{ }^{2-}\right]$ MIL exhibited a viscosity of $91030 \mathrm{cP}$ at $21.4{ }^{\circ} \mathrm{C}$, which falls within the previously reported viscosity values of $112300 \mathrm{cP}\left(20^{\circ} \mathrm{C}\right)$ and $75230 \mathrm{cP}\left(25^{\circ} \mathrm{C}\right)$ [36]. The viscosity of the $\left[\text { Aliquat }^{+}\right]_{2}\left[\mathrm{MnCl}_{4}{ }^{2-}\right] \mathrm{MIL}$ exceeded the working range of the instrument (103500 cP).

\subsection{Method optimization}


Several extraction parameters were optimized for the DLLME method using both MILs. For the $\left[\mathrm{P}_{6,6,6,14}{ }^{+}\right]_{2}\left[\mathrm{MnCl}_{4}{ }^{2-}\right] \mathrm{MIL}$, the disperser solvents acetonitrile, acetone, and methanol were examined. The effects of MIL mass (5 to $20 \mathrm{mg}$ ), extraction time (30 s to $120 \mathrm{~s}$ ), disperser solvent volume (5 to $20 \mu \mathrm{L}$ ), and salt concentration ( 0 to $30 \% \mathrm{NaCl}(\mathrm{w} / \mathrm{v})$ ) were subsequently studied. For the $\left[\text { Aliquat }^{+}\right]_{2}\left[\mathrm{MnCl}_{4}{ }^{2-}\right] \mathrm{MIL}$, optimization of disperser solvent type, disperser solvent volume, and extraction time were performed using the same conditions applied for the $\left[\mathrm{P}_{6,6,6,14}{ }^{+}\right]_{2}\left[\mathrm{MnCl}_{4}{ }^{2-}\right] \mathrm{MIL}$.

In the HS-SDME experiments, the amount of salt in the aqueous sample (0 to $30 \% \mathrm{NaCl}$ (w/v)), as well as effect of temperature $\left(20,40,60^{\circ} \mathrm{C}\right.$ ), mass of MIL microdroplet (5 to $20 \mathrm{mg}$ ), extraction time (5 to $75 \mathrm{~min}$ ), stir rate (400 to $1100 \mathrm{rpm}$ ), and headspace volume (2.5 and $4 \mathrm{~mL}$ ) were investigated.

\subsection{Procedures}

\subsubsection{Dispersive liquid-liquid microextraction (DLLME)}

The DLLME method was performed by first homogenizing $20 \mathrm{mg}$ of the $\left[\mathrm{P}_{6,6,6,14^{+}}\right]_{2}\left[\mathrm{MnCl}_{4}{ }^{2-}\right] \mathrm{MIL}$ with $20 \mu \mathrm{L}$ of acetonitrile. The mixture was pipetted into a vial containing an appropriate concentration of analyte solution made with $6 \mathrm{~mL}$ of an aqueous solution of $30 \% \mathrm{NaCl}(\mathrm{w} / \mathrm{v})$. The vial was immediately capped and manually agitated for 2 minutes. A rod magnet $(0.66 \mathrm{~T})$ was used to collect the MIL microdroplets from the aqueous solution. The collected MIL was dissolved in $20 \mu \mathrm{L}$ of acetonitrile and subjected to HPLC analysis. All extractions were performed in $7 \mathrm{~mL}$ screw cap glass vials. For the [Aliquat $\left.{ }^{+}\right]_{2}\left[\mathrm{MnCl}_{4}{ }^{2-}\right] \mathrm{MIL}$, the same procedure was applied with $5 \mu \mathrm{L}$ of methanol as disperser solvent and 1 minute of manual agitation. 


\subsubsection{Headspace single drop microextraction (HS-SDME)}

In the HS-SDME method, $20 \mathrm{mg}$ of the MIL was held on the bottom of the rod magnet, which was tightly inserted into a PTFE silicone septum of a screw cap. A small stir bar was added to $6 \mathrm{~mL}$ of the aqueous sample solution prepared with $30 \% \mathrm{NaCl}(\mathrm{w} / \mathrm{v})$. The vial was capped and the aqueous solution was stirred for 60 minutes at $400 \mathrm{rpm}$ and $800 \mathrm{rpm}$ for the $\left[\mathrm{P}_{6,6,6,14^{+}}\right]_{2}\left[\mathrm{MnCl}_{4}{ }^{2-}\right]$ and the $\left[\text { Aliquat }{ }^{+}\right]_{2}\left[\mathrm{MnCl}_{4}{ }^{2-}\right] \mathrm{MILs}$, respectively. The extraction temperature was kept at $60^{\circ} \mathrm{C}$ for the $\left[\mathrm{P}_{6,6,6,14}{ }^{+}\right]_{2}\left[\mathrm{MnCl}_{4}{ }^{2-}\right] \mathrm{MIL}$ and $40^{\circ} \mathrm{C}$ for the $\left[\text { Aliquat }{ }^{+}\right]_{2}\left[\mathrm{MnCl}_{4}{ }^{2-}\right] \mathrm{MIL}$. Stir bars and rod magnets were washed with acetonitrile, acetone, and deionized water following the extractions to minimize any carryover effects. The analyte enriched MIL microdroplet was dissolved in $20 \mu \mathrm{L}$ of acetonitrile and subjected to HPLC analysis.

\subsubsection{Method validation}

The analytical performance of the optimized method was evaluated in ultrapure water. A calibration curve for each analyte was obtained by examining peak areas of extracted analytes at different concentration levels. The LOD was determined by decreasing the analyte concentration until a signal to noise ratio of 3 was acquired. Lake water was collected from a local lake (Ames, IA, USA) and used to evaluate the relative recovery of analytes. Nylon filters $(0.45 \mu \mathrm{m})$ were used to filter the water samples prior to all extractions.

\section{Results and discussion}

\subsection{Optimization of the DLLME method}


Several parameters for the DLLME method including the disperser solvent type, mass of MIL, extraction time, disperser solvent volume, and the ionic strength of the aqueous sample solution were optimized using a factor by factor approach. The optimization was originally performed with the $\left[\mathrm{P}_{6,6,6,14}{ }^{+}\right]_{2}\left[\mathrm{MnCl}_{4}{ }^{2-}\right] \mathrm{MIL}$. A disperser solvent is used in DLLME to assist in creating fine microdroplets of the extraction solvent within the sample solution. An ideal disperser solvent should be miscible with both the extraction solvent and the sample matrix [21]. In this study, acetonitrile, methanol, and acetone were examined as disperser solvents. Acetonitrile provided the highest peak areas for most of the analytes, whereas acetone resulted in the lowest peak areas for all analytes except anthracene (see Figure S1). In addition, a lower precision was observed when acetone was used as dispersive solvent, with relative standard deviation (RSD) values varying from $4.6 \%$ to $24.7 \%$. Thus, acetonitrile was selected as disperser solvent for the $\left[\mathrm{P}_{6,6,6,14}{ }^{+}\right]_{2}\left[\mathrm{MnCl}_{4}{ }^{2-}\right] \mathrm{MIL}$.

In order to study the effect of extraction solvent mass on extraction efficiencies, four different masses $(5,10,15,20 \mathrm{mg})$ of MIL were examined. Higher extraction efficiencies were observed for all analytes when the mass of MIL was increased up to $15 \mathrm{mg}$, as shown in Figure S2. Further increasing the MIL mass to $20 \mathrm{mg}$ provided a significant increase in peak areas for fluorene, phenanthrene, and anthracene, whereas comparable peak areas were observed for all other analytes. The increase in extraction efficiency with higher mass of MIL may be the result of more droplets forming during the extraction, while the solubility of the droplets is minimized by the use of hydrophobic MILs. Similar observations were made in previous DLLME studies $[19,31,38]$. Therefore, a mass of $20 \mathrm{mg}$ was used for all subsequent extractions.

As the extraction solvent is dispersed into fine droplets within the sample solution, analyte molecules quickly partition into the extraction phase due to the high surface area of the 
extraction solvent [12]. Extraction time is an important variable in DLLME as a sufficient amount of time should be given to allow equilibration between the sample solution and the extraction solvent. Extraction times from 30 to 120 seconds were examined in this study. Sorption-time profiles for the DLLME method using the $\left[\mathrm{P}_{6,6,6,614^{+}}\right]_{2}\left[\mathrm{MnCl}_{4}{ }^{2-}\right]$ MIL are represented in Figure 1. A steady increase in peak area was observed for acetophenone, 1-chloro4-nitrobenzene, 2-nitronaphthalene, benzophenone, and phenanthrene when the extraction time was increased from $30 \mathrm{~s}$ to $120 \mathrm{~s}$. Profiles of 2-chloroaniline, $\alpha, \alpha, \alpha$-6-tetrafluoro-m-toluidine, fluorene, and anthracene plateaued following an extraction time of $90 \mathrm{~s}$, and a similar observation can be made for 2-bromo-4-fluorobenzaldehyde, 4-chlorobutyrophenone, and biphenyl. In order to find the optimal extraction time for all analytes while maintaining high enrichment factors, an extraction time of $120 \mathrm{~s}$ was selected for the $\left[\mathrm{P}_{6,6,6,14}{ }^{+}\right]_{2}\left[\mathrm{MnCl}_{4}{ }^{2-}\right] \mathrm{MIL}$.

The influence of the disperser solvent volume was also evaluated. The use of high volumes of disperser solvent may increase the solubility of analytes in the organic solvent, whereas insufficient volumes of disperser solvent can result in poor dispersion of the extraction solvent. In order to assess the effect of disperser solvent volume, acetonitrile volumes from 5 to $20 \mu \mathrm{L}$ were examined. Figure 2 shows that the disperser solvent volume did not produce a significant difference in extraction efficiencies for those analytes possessing lower molecular weight and relatively high volatility. However, the extraction efficiencies of PAHs were greatly affected by the disperser solvent volume. The optimal extraction performance exhibited by an acetonitrile volume of $20 \mu \mathrm{L}$ appears to result from a superior dispersion of the MIL in the sample solution.

The addition of kosmotropic salt to the aqueous sample solution prior to extraction can increase analyte extraction efficiencies due to the salting out effect. Elevated concentrations of 
kosmotropic salts in aqueous solution causes ordering of water molecules and diminished solvation of analytes, resulting in the transfer of analyte molecules to the organic phase, headspace, or extraction phase [39-42]. Therefore, the influence of the ionic strength was examined using $\mathrm{NaCl}$ concentrations ranging from 0 to $30 \%(\mathrm{w} / \mathrm{v})$. In general, higher extraction efficiencies were observed with an increase in the salt concentration, as shown in Figure S3 of supporting information. Fluorene, phenanthrene, and anthracene exhibited similar or slightly higher peak areas when a $10 \%(\mathrm{w} / \mathrm{v}) \mathrm{NaCl}$ solution was used. A slight decrease in peak areas were observed for the three PAHs when the salt concentration was increased from 10 to $20 \%$ $(\mathrm{w} / \mathrm{v})$, and those of $30 \%(\mathrm{w} / \mathrm{v})$ were comparable to peak areas at $20 \%$ salt content $(\mathrm{w} / \mathrm{v})$. One possible reason could be that PAHs, possessing high hydrophobicity and relatively low volatility, may be prone to wall adsorption [43]. In addition, increased extraction efficiencies due to the salting out effect is generally demonstrated more effectively for more polar molecules [4]. To find a compromised extraction condition that provides the optimal extraction efficiencies for most of the studied analytes, a 30\% (w/v) $\mathrm{NaCl}$ aqueous sample solution was used for subsequent extractions.

Following optimization of the DLLME method using the $\left[\mathrm{P}_{6,6,6,14^{+}}\right]_{2}\left[\mathrm{MnCl}_{4}{ }^{2-}\right]$ MIL, a separate optimization procedure was performed using the $\left[\text { Aliquat }{ }^{+}\right]_{2}\left[\mathrm{MnCl}_{4}{ }^{2-}\right]$ MIL. Based on experimental results obtained from the optimization studies using the $\left[\mathrm{P}_{6,6,6,14^{+}}{ }^{+}{ }_{2}\left[\mathrm{MnCl}_{4}{ }^{2-}\right] \mathrm{MIL}\right.$, $20 \mathrm{mg}$ of the $\left[\text { Aliquat }{ }^{+}\right]_{2}\left[\mathrm{MnCl}_{4}{ }^{2-}\right] \mathrm{MIL}$ and $30 \%(\mathrm{w} / \mathrm{v}) \mathrm{NaCl}$ concentration were applied to all extractions. The remaining parameters, including disperser solvent type, disperser solvent volume, and extraction time were optimized as single variables using the DLLME method.

For the $\left[\text { Aliquat }{ }^{+}\right]_{2}\left[\mathrm{MnCl}_{4}{ }^{2-}\right] \mathrm{MIL}$, methanol provided the highest peak areas when used as the disperser solvent, as shown in Figure S4. Peak areas for acetophenone, 2-bromo-4- 
fluorobenzaldehyde, and 1-chloro-4-nitrobenzene were larger using acetonitrile as the disperser solvent, but the differences were not significant. Similar to that of the $\left[\mathrm{P}_{6,6,6,14^{+}}\right]_{2}\left[\mathrm{MnCl}_{4}{ }^{2-}\right] \mathrm{MIL}$, acetone produced not only the lowest extraction efficiencies, but also lower reproducibility compared to methanol and acetonitrile. Therefore, methanol was selected as the disperser solvent for the [Aliquat $\left.{ }^{+}\right]_{2}\left[\mathrm{MnCl}_{4}{ }^{2-}\right] \mathrm{MIL}$.

The influence of disperser solvent volume was also assessed for the [Aliquat $\left.{ }^{+}\right]_{2}\left[\mathrm{MnCl}_{4}{ }^{2-}\right]$ MIL by performing extractions using 5 to $20 \mu \mathrm{L}$ of methanol as disperser solvent. As shown in Figure $3,5 \mu \mathrm{L}$ of disperser solvent provided the highest peak areas for all analytes, with the exception of acetophenone. A dramatic decrease in peak area was observed for all analytes other than acetophenone when the disperser solvent volume was increased from 5 to $10 \mu \mathrm{L}$, and relatively small increase in extraction efficiencies was obtained when the disperser solvent volume was further increased to $20 \mu \mathrm{L}$. Decreased extraction efficiencies have been observed in other studies when high volumes of disperser solvent were used, which lead to increased solubility of the extraction solvent in the aqueous phase $[12,18,44,45]$. Thus, $5 \mu \mathrm{L}$ of methanol was chosen as disperser solvent volume for this MIL.

Extraction times from 30 to 120 seconds were also studied for the [Aliquat $\left.{ }^{+}\right]_{2}\left[\mathrm{MnCl}_{4}{ }^{2-}\right]$ MIL. Unlike the results found with the $\left[\mathrm{P}_{6,6,6,14^{+}}\right]_{2}\left[\mathrm{MnCl}_{4}{ }^{2-}\right] \mathrm{MIL}$, it can be observed in Figure 4 that no notable trend was observed with varying extraction time. Only acetophenone exhibited a continual increase in peak areas with prolonged extraction time, where a maximum peak area was attained at approximately $120 \mathrm{~s}$. For the majority of the analytes, extraction times of 60 and $90 \mathrm{~s}$ provided similar peak areas. At an extraction time of $120 \mathrm{~s}$, it was observed that the amount of MIL collected by the magnet following extraction was appreciably lower compared to shorter 
extraction times. Given the aforementioned results, 60 seconds was used for all subsequent extractions with the $\left[\text { Aliquat }{ }^{+}\right]_{2}\left[\mathrm{MnCl}_{4}{ }^{2-}\right] \mathrm{MIL}$.

\subsection{Optimization of the HS-SDME method}

The parameters evaluated for the HS-SDME method included: salt concentration in the aqueous solution, temperature of the extraction system, extraction time, stir rate, and headspace volume. These parameters were studied for the $\left[\mathrm{P}_{6,6,6,14}{ }^{+}\right]_{2}\left[\mathrm{MnCl}_{4}{ }^{2-}\right]$ and $\left[\text { Aliquat }^{+}\right]_{2}\left[\mathrm{MnCl}_{4}{ }^{2-}\right]$ MILs. The salting out effect for the HS-SDME method was evaluated for aqueous solutions containing 0 to $30 \%(\mathrm{w} / \mathrm{v})$ of $\mathrm{NaCl}$. The effect of $\mathrm{NaCl}$ concentration on the analyte extraction efficiencies for the $\left[\mathrm{P}_{6,6,6,14}{ }^{+}\right]_{2}\left[\mathrm{MnCl}_{4}{ }^{2-}\right]$ and $\left[\text { Aliquat }^{+}\right]_{2}\left[\mathrm{MnCl}_{4}{ }^{2-}\right]$ MILs is shown in Figures S5. For both MILs, increased peak areas were observed for the majority of the analytes with an increase in the $\mathrm{NaCl}$ concentration. The salting out effect was much less pronounced for phenanthrene and anthracene; in fact, the peak areas were slightly higher for the two PAHs when no salt was added to the aqueous solution. To achieve optimal extraction performance for the majority of analytes, a $30 \%(w / v) ~ N a C l$ concentration was chosen for all HS-SDME extractions.

Partitioning of analyte molecules from the aqueous solution to the headspace and from the headspace to the extraction phase is affected by the temperature at which the extraction is carried out [8]. Use of elevated temperature shortens the equilibrium time due to increased diffusion coefficients of the analytes in the liquid phase [46]. Extraction efficiencies of the target analytes were studied by performing extractions at $20^{\circ} \mathrm{C}, 40^{\circ} \mathrm{C}$, and $60^{\circ} \mathrm{C}$. As shown in Figure 5 , all analytes exhibited appreciably higher peak areas for the $\left[\mathrm{P}_{6,6,6,14}{ }^{+}\right]_{2}\left[\mathrm{MnCl}_{4}{ }^{2-}\right] \mathrm{MIL}$ when the temperature of the system was increased. PAHs exhibited an especially notable increase in peak area from 40 to $60^{\circ} \mathrm{C}$. Interestingly, a different trend was observed for the $\left[\text { Aliquat }{ }^{+}\right]_{2}\left[\mathrm{MnCl}_{4}{ }^{2-}\right]$ 
MIL when the temperature was increased. Benzophenone, 2-nitronaphthalene, fluorene, phenanthrene, and anthracene, which possess low vapor pressures, exhibited higher peak areas when an extraction temperature of $60^{\circ} \mathrm{C}$ was used, whereas other analytes showed either highest extraction efficiencies at $40^{\circ} \mathrm{C}$ or no discernable difference between $20^{\circ} \mathrm{C}$ and $40^{\circ} \mathrm{C}$. This result indicates that increasing the system temperature not only increased the concentration of analytes in the headspace, but also enhances the partitioning of these analytes into the extraction solvent. However, collecting a consistent amount of the $\left[\text { Aliquat }{ }^{+}\right]_{2}\left[\mathrm{MnCl}_{4}{ }^{2-}\right] \mathrm{MIL}$ was found to be challenging when extractions were performed at $60^{\circ} \mathrm{C}$, leading to lower reproducibility. Considering these results, $40^{\circ} \mathrm{C}$ and $60^{\circ} \mathrm{C}$ were selected as the optimal extraction temperatures for the $\left[\text { Aliquat }{ }^{+}\right]_{2}\left[\mathrm{MnCl}_{4}{ }^{2-}\right]$ and the $\left[\mathrm{P}_{6,6,6,14}{ }^{+}\right]_{2}\left[\mathrm{MnCl}_{4}{ }^{2-}\right]$ MILs, respectively.

One of the major advantages of using MILs over traditional organic solvents in SDME is the overall droplet stability. In conventional SDME, a microsyringe is often used to sustain the extraction solvent, in which case the volume of extraction solvent is limited by the small contact area between the syringe tip and the solvent droplet [10]. With MILs, the magnet assists in maintaining the extraction solvent static, which greatly improves the stability of the droplet and permits the use of higher extraction solvent volumes. Theoretically, higher volumes of extraction solvent provide higher enrichment of analytes [9]. The influence of MIL mass was studied by performing extractions using 5, 10, 15, and $20 \mathrm{mg}$ of the MILs. As shown in Figure S6(A) for the $\left[\mathrm{P}_{6,6,6,14}{ }^{+}\right]_{2}\left[\mathrm{MnCl}_{4}{ }^{2-}\right] \mathrm{MIL}$, a larger mass of MIL resulted in higher peak areas for all analytes, with a significant difference in extraction efficiencies between 5 and $10 \mathrm{mg}$. On the other hand, the $\left[\text { Aliquat }{ }^{+}\right]_{2}\left[\mathrm{MnCl}_{4}{ }^{2-}\right]$ MIL (Figure S6(B)) showed less pronounced differences in extraction efficiencies as the MIL microdroplet mass was increased. Consequently, $20 \mathrm{mg}$ was chosen as the optimum MIL mass for the subsequent experiments. 
Extraction time is an important parameter to investigate in SDME to achieve good precision as well as satisfactory enrichment of the analytes as the mass transfer process is dependent on time [10]. In non-exhaustive extraction methods such as HS-SDME, identifying the time in which the three phases attain equilibrium allows for the development of a method to achieve the highest extraction efficiencies [47]. Therefore, extraction times from 5 to 75 minutes were examined. Sorption-time profiles of the analytes are shown in Figure 6 for the $\left[\mathrm{P}_{6,6,6,14^{+}}\right]_{2}\left[\mathrm{MnCl}_{4}{ }^{2-}\right]$ and $\left[\text { Aliquat }{ }^{+}\right]_{2}\left[\mathrm{MnCl}_{4}{ }^{2-}\right]$ MILs using the optimal extraction temperatures for each MIL. The analytes with relatively high vapor pressure reached equilibrium within 60 minutes. On the other hand, analytes with higher molecular weight and lower vapor pressure, such as fluorene, phenanthrene and anthracene, exhibited highest extraction efficiencies at 75 minutes. Analytes that possess high molecular weight and low volatility are often expected to require longer time to reach equilibrium in the headspace extraction mode [47]. Therefore, 60 minutes was chosen as the optimal extraction time for both the $\left[\text { Aliquat }{ }^{+}\right]_{2}\left[\mathrm{MnCl}_{4}{ }^{2-}\right]$ and the $\left[\mathrm{P}_{6,6,6,14}{ }^{+}\right]_{2}\left[\mathrm{MnCl}_{4}{ }^{2-}\right] \mathrm{MILs}$.

More rapid equilibrium of the analyte between the aqueous sample solution and the headspace can be achieved when higher stir rate is applied [48]. Sufficient agitation should be provided throughout the extraction to promote mass transfer of the target analytes into the headspace. A series of extractions was performed using stir rates of 400, 800, and $1100 \mathrm{rpm}$. The lowest stir rate $(400 \mathrm{rpm})$ provided the highest extraction efficiencies for the $\left[\mathrm{P}_{6,6,6,14}{ }^{+}\right]_{2}\left[\mathrm{MnCl}_{4}{ }^{2-}\right]$ MIL, as shown in Figure S7. Extractions performed at $60^{\circ} \mathrm{C}$ required relatively lower stir rates to provide necessary convection for analytes to reach equilibrium, owing to the fact that the mass transfer rate increases in heated extraction systems [3]. For the [Aliquat $\left.{ }^{+}\right]_{2}\left[\mathrm{MnCl}_{4}{ }^{2-}\right] \mathrm{MIL}, \mathrm{a}$ higher stir rate $(800 \mathrm{rpm})$ was required to attain the maximum extraction efficiencies. Hence, 400 
rpm and $800 \mathrm{rpm}$ were chosen as stir rates for the $\left[\mathrm{P}_{6,6,6,14}{ }^{+}\right]_{2}\left[\mathrm{MnCl}_{4}{ }^{2-}\right]$ and $\left[\text { Aliquat }{ }^{+}\right]_{2}\left[\mathrm{MnCl}_{4}{ }^{2-}\right]$ MILs, respectively.

Theoretically, the headspace volume should be kept to a minimum in order to increase extraction efficiency, as increasing the headspace volume consequently decreases the concentration of analytes in the vapor phase [11, 49]. Extractions were performed using headspace volumes of $2.5 \mathrm{~mL}$ and $4 \mathrm{~mL}$. A 60 minute extraction time was chosen for the $\left[\mathrm{P}_{6,6,6,14^{+}}\right]_{2}\left[\mathrm{MnCl}_{4}{ }^{2-}\right] \mathrm{MIL}$ at $60^{\circ} \mathrm{C}$ and for the $\left[\text { Aliquat }{ }^{+}\right]_{2}\left[\mathrm{MnCl}_{4}{ }^{2-}\right] \mathrm{MIL}$ at $40^{\circ} \mathrm{C}$. The aqueous sample volume was kept at $6 \mathrm{~mL}$ for consistency. As expected, higher analyte extraction efficiencies were observed for both MILs when a headspace volume of $2.5 \mathrm{~mL}$ was employed (see Figure S8). Therefore, a headspace volume of $2.5 \mathrm{~mL}$ was employed in further extractions.

\subsection{Quality parameters and comparison of the methods}

Low background absorbance was observed with the $\left[\mathrm{P}_{6,6,6,14}{ }^{+}\right]_{2}\left[\mathrm{MnCl}_{4}{ }^{2-}\right] \mathrm{MIL}$ in the chromatograms shown in Figure S9. Additionally, the $\left[\mathrm{P}_{6,6,6,14}{ }^{+}\right]_{2}\left[\mathrm{MnCl}_{4}{ }^{2-}\right]$ MIL exhibited higher extraction efficiencies for all analytes compared to the $\left[\text { Aliquat }^{+}\right]_{2}\left[\mathrm{MnCl}_{4}{ }^{2-}\right] \mathrm{MIL}$ in both DLLME and HS-SDME methods under the optimized conditions. Therefore, the analytical performance of the method was evaluated using the optimized parameters with the $\left[\mathrm{P}_{6,6,6,14^{+}}\right]_{2}\left[\mathrm{MnCl}_{4}{ }^{2-}\right] \mathrm{MIL}$ based on calibration curves containing eight to eleven concentration levels. The linear range, coefficient of determination $\left(\mathrm{R}^{2}\right)$, limits of detection (LOD), and reproducibility were assessed and are reported in Tables 1 and 2. Coefficients of determination $\left(\mathrm{R}^{2}\right)$ varied from 0.997 to 0.999 in the DLLME method and from 0.994 to 0.999 in the HSSDME method. The LODs varied from $0.05 \mu \mathrm{g} \mathrm{L}^{-1}$ to $1.0 \mu \mathrm{g} \mathrm{L}^{-1}$ for the DLLME method and from $0.04 \mu \mathrm{g} \mathrm{L}^{-1}$ to $1.0 \mu \mathrm{g} \mathrm{L} \mathrm{L}^{-1}$ when the HS-SDME method was used. The reproducibility of both 
methods was evaluated at three different spiked concentration levels, namely, 5, 20, and $300 \mu \mathrm{g}$ $\mathrm{L}^{-1}(\mathrm{n}=3)$. For the DLLME method, RSDs ranged between $0.3 \%$ and $15 \%$ at $5 \mu \mathrm{g} \mathrm{L}{ }^{-1}$. Similarly, RSDs for the HS-SDME method oscillated from 1.8 to $13.8 \%$ at $5 \mu \mathrm{g} \mathrm{L}{ }^{-1}$.

The enrichment factor $\left(\mathrm{E}_{\mathrm{F}}\right)$ was used to evaluate the extraction performance of both methods. $\mathrm{E}_{\mathrm{F}}$ values were calculated according to Equation 1 below:

$$
\mathrm{E}_{\mathrm{F}}=\frac{\mathrm{C}_{\mathrm{MLL}}}{\mathrm{C}_{\text {initial }}}
$$

where $\mathrm{C}_{\mathrm{MIL}}$ is the concentration of the analytes in the MIL droplet following the extraction and $\mathrm{C}_{\text {initial }}$ is the initial concentration of analyte in the aqueous solution. $\mathrm{C}_{\mathrm{MIL}}$ was calculated from calibration curves based on the direct injection of standard solutions. Table 3 lists the calculated $E_{F}$ values at a spiked concentration of $60 \mu \mathrm{g} \mathrm{L}^{-1}$. The HS-SDME method using the $\left[\mathrm{P}_{6,6,6,6,14^{+}}\right]_{2}\left[\mathrm{MnCl}_{4}{ }^{2-}\right]$ MIL resulted in higher enrichment factors for $\alpha, \alpha, \alpha-6$-tetrafluoro-mtoluidine, 2-bromo-4-fluorobenzaldehyde, 1-chloro-4-nitrobenzene, biphenyl, and fluorene in comparison to the DLLME method. However, the DLLME method provided higher enrichment factors for the other seven analytes. The developed DLLME method permits a much faster extraction ( 2 minutes) while providing higher enrichment for many of the target analytes compared to the HS-SDME method (extraction time of $60 \mathrm{~min}$ ). Additionally, temperature control is not required for the DLLME method. On the other hand, the developed SDME method maintains an advantage when sampling from complex matrices as the MIL microdroplet never comes in direct contact with the sample solution. Compared to other microextraction techniques, the developed MIL-HS-SDME method exhibits advantages such as the ability to use higher volume of extraction solvent and elimination of a desorption step, as shown in Table S2. This further highlights the applicability of MILs in sample preparation techniques. 


\subsection{Analysis of real samples}

Following the optimization and validation of the DLLME and the HS-SDME methods with the $\left[\mathrm{P}_{6,6,6,14}{ }^{+}\right]_{2}\left[\mathrm{MnCl}_{4}{ }^{2-}\right] \mathrm{MIL}$, the analysis of a real lake water sample was performed. The $\mathrm{NaCl}$ content of the real sample was adjusted to $30 \%(\mathrm{w} / \mathrm{v})$ based on the previously described experimental results. No analytes were detected in the unadulterated lake water sample. Table 4 shows the relative recoveries and the reproducibility obtained using both methods at $20 \mu \mathrm{g} \mathrm{L} \mathrm{L}^{-1}$ and $100 \mu \mathrm{g} \mathrm{L}^{-1}(\mathrm{n}=3)$. The relative recoveries for the DLLME method ranged from $68.7 \%$ to $104.5 \%$ at $20 \mu \mathrm{g} \mathrm{L} \mathrm{L}^{-1}$ and from $72.7 \%$ to $108.2 \%$ at $100 \mu \mathrm{g} \mathrm{L}^{-1}$. The relative recovery values varied from $70.2 \%$ to $109.6 \%$ at $20 \mu \mathrm{g} \mathrm{L}^{-1}$ and from $66.8 \%$ to $109.2 \%$ at $100 \mu \mathrm{g} \mathrm{L}^{-1}$ for the HSSDME method. Relatively low recovery values were observed for some analytes using both methods, which can be explained by matrix effect. The standard deviation values for the recoveries were at or below $14.9 \%$. These results demonstrate that the developed methods exhibited good reproducibility and sensitivity when applied to real world samples.

\section{Conclusions}

Two hydrophobic, tetrachloromanganate-based MILs were successfully applied for the first time as extraction solvents in HS-SDME coupled to HPLC. The magnetic susceptibility of the MILs imparted high stability to the microdroplet permitting sampling under elevated temperatures and long extraction times. Following extraction, the analyte-enriched droplet was directly subjected to HPLC analysis. The optimized HS-SDME method was directly compared to the DLLME method employing the same two MILs as extraction solvents. The DLLME method provided much faster extraction time and higher enrichment for analytes with low vapor pressure, whereas HS-SDME showed advantages in extracting analytes possessing relatively high vapor 
pressure. Both methods exhibited low LODs and high precision for the target analytes as well as acceptable relative recoveries from a lake water sample, indicating that the examined MILs can be successfully applied in microextraction techniques. The total sampling time required of the DLLME method was less than 5 minutes, which demonstrates its potential as a high throughput sampling technique. Longer sampling time was necessary for the HS-SDME method. However, the HS-SDME method can be easily employed in cases of complex matrices since it is not necessary for the extraction solvent to be subjected to the sample solution.

The use of $\left[\mathrm{MnCl}_{4}{ }^{2-}\right]$-based MILs provides tremendous advantages over the conventional DLLME and HS-SDME methods as they provide more convenient ways to perform extractions. Also, the low UV absorbance of the $\left[\mathrm{MnCl}_{4}{ }^{2-}\right]$-based MILs permits the direct coupling to HPLC for chromatographic analysis. Furthermore, the selectivity of the extraction solvent can be varied by altering the substituent groups on the cationic component. These advantages provide attractive features when using MILs for the two microextraction techniques examined in this study, particularly in the development of high throughput and automated methods that can be compatible with complex matrices.

\section{Acknowledgements}

The authors acknowledge funding from the Chemical Measurement and Imaging Program at the National Science Foundation (Grant number CHE-1413199). 


\section{References}

[1] S. Jahan, H. Xie, R. Zhong, J. Yan, H. Xiao, L. Fan, C. Cao, A highly efficient three-phase single drop microextraction technique for sample preconcentration, Analyst 140 (2015) 31933200.

[2] A. Zgoła-Grześkowiak, T. Grześkowiak, Dispersive liquid-liquid microextraction, Trends Anal. Chem. 30 (2011) 1382-1399.

[3] J. Pawliszyn, Sample preparation: quo vadis?, Anal. Chem. 75 (2003) 2543-2558.

[4] E. Psillakis, N. Kalogerakis, Developments in single-drop microextraction, Trends Anal. Chem. 21 (2002) 53-63.

[5] L. Xu, C. Basheer, H.K. Lee, Developments in single-drop microextraction, J. Chromatogr. A 1152 (2007) 184-192.

[6] J. Pawliszyn, S. Pedersen-Bjergaard, Analytical microextraction: current status and future trends, J. Chromatogr. Sci. 44 (2006) 291-307.

[7] M. Rezaee, Y. Assadi, M.R. Milani Hosseini, E. Aghaee, F. Ahmadi, S. Berijani, Determination of organic compounds in water using dispersive liquid-liquid microextraction, J. Chromatogr. A 1116 (2006) 1-9.

[8] H. Liu, P. K. Dasgupta, Analytical chemistry in a drop. solvent extraction in a microdrop, Anal. Chem. 68 (1996) 1817-1821.

[9] A. Przyjazny, J. M. Kokosa, Analytical characteristics of the determination of benzene, toluene, ethylbenzene and xylenes in water by headspace solvent microextraction, J. Chromatogr. A 977 (2002) 143-153. 
[10] L. Kocurova, I.S. Balogh, V. Andruch, A glance at achievements in the coupling of headspace and direct immersion single-drop microextraction with chromatographic techniques, J. Sep. Sci. 36 (2013) 3758-3768.

[11] M.A. Jeannot, A. Przyjazny, J.M. Kokosa, Single drop microextraction-development, applications and future trends, J. Chromatogr. A 1217 (2010) 2326-2336.

[12] M.T. Pena, M.C. Casais, M.C. Mejuto, R. Cela, Development of an ionic liquid based dispersive liquid-liquid microextraction method for the analysis of polycyclic aromatic hydrocarbons in water samples, J. Chromatogr. A 1216 (2009) 6356-6364.

[13] Y. He, A. Vargas, Y.J. Kang, Headspace liquid-phase microextraction of methamphetamine and amphetamine in urine by an aqueous drop, Anal. Chim. Acta 589 (2007) 225-230.

[14] Y. Liu, E. Zhao, W. Zhu, H. Gao, Z. Zhou, Determination of four heterocyclic insecticides by ionic liquid dispersive liquid-liquid microextraction in water samples, J. Chromatogr. A 1216 (2009) 885-891.

[15] T.D. Ho, C. Zhang, L.W. Hantao, J.L. Anderson, Ionic liquids in analytical chemistry: fundamentals, advances, and perspectives, Anal. Chem. 86 (2014) 262-285.

[16] C. Yao, W. R. Pitner, J. L. Anderson, Ionic liquids containing the tris(pentafluoroethyl)trifluorophosphate anion: a new class of highly selective and ultra hydrophobic solvents for the extraction of polycyclic aromatic hydrocarbons using single drop microextraction, Anal. Chem. 81 (2009) 5054-5063.

[17] J. Liu, G. Jiang, Y. Chi, Y. Cai, Q. Zhou, J. Hu, Use of ionic liquids for liquid-phase microextraction of polycyclic aromatic hydrocarbons, Anal. Chem. 75 (2003) 5870-5876. 
[18] L. He, X. Luo, H. Xie, C. Wang, X. Jiang, K. Lu, Ionic liquid-based dispersive liquid-liquid microextraction followed high-performance liquid chromatography for the determination of organophosphorus pesticides in water sample, Anal. Chim. Acta 655 (2009) 52-59.

[19] L.M. Ravelo-Perez, J. Hernandez-Borges, M. Asensio-Ramos, M.A. Rodriguez-Delgado, Ionic liquid based dispersive liquid-liquid microextraction for the extraction of pesticides from bananas, J. Chromatogr. A 1216 (2009) 7336-7345.

[20] F.Q. Zhao, J. Li, B.Z. Zeng, Coupling of ionic liquid-based headspace single-drop microextraction with GC for sensitive detection of phenols, J. Sep. Sci. 31 (2008) 3045-3049.

[21] J. Lopez-Darias, M. German-Hernandez, V. Pino, A.M. Afonso, Dispersive liquid-liquid microextraction versus single-drop microextraction for the determination of several endocrinedisrupting phenols from seawaters, Talanta 80 (2010) 1611-1618.

[22] E.M. Martinis, P. Berton, J.C. Altamirano, U. Hakala, R.G. Wuilloud, Tetradecyl(trihexyl)phosphonium chloride ionic liquid single-drop microextraction for electrothermal atomic absorption spectrometric determination of lead in water samples, Talanta 80 (2010) 2034-2040.

[23] S. Li, S. Cai, W. Hu, H. Chen, H. Liu, Ionic liquid-based ultrasound-assisted dispersive liquid-liquid microextraction combined with electrothermal atomic absorption spectrometry for a sensitive determination of cadmium in water samples, Spectrochim. Acta B 64 (2009) 666-671. [24] J. Werner, Determination of metal ions in tea samples using task-specific ionic liquid-based ultrasound-assisted dispersive liquid-liquid microextraction coupled to liquid chromatography with ultraviolet detection, J. Sep. Sci. 39 (2016) 1411-1417.

[25] K.D. Clark, O. Nacham, J.A. Purslow, S.A. Pierson, J.L. Anderson, Magnetic ionic liquids in analytical chemistry: a review, Anal. Chim. Acta 934 (2016) 9-21. 
[26] K.D. Clark, O. Nacham, H. Yu, T. Li, M.M. Yamsek, D.R. Ronning, J.L. Anderson, Extraction of DNA by magnetic ionic liquids: tunable solvents for rapid and selective DNA analysis, Anal. Chem. 87 (2015) 1552-1559.

[27] H. Yu, J. Merib, J.L. Anderson, Faster dispersive liquid-liquid microextraction methods using magnetic ionic liquids as solvents, J. Chromatogr. A 1463 (2016) 11-19.

[28] A. Beiraghi, M. Shokri, S. Seidi, B.M. Godajdar, Magnetomotive room temperature dicationic ionic liquid: a new concept toward centrifuge-less dispersive liquid-liquid microextraction, J. Chromatogr. A 1376 (2015) 1-8.

[29] N. Deng, M. Li, L. Zhao, C. Lu, S.L. de Rooy, I.M. Warner, Highly efficient extraction of phenolic compounds by use of magnetic room temperature ionic liquids for environmental remediation, J. Hazard. Mater. 192 (2011) 1350-1357.

[30] M.J. Trujillo-Rodriguez, O. Nacham, K.D. Clark, V. Pino, J.L. Anderson, J.H. Ayala, A.M. Afonso, Magnetic ionic liquids as non-conventional extraction solvents for the determination of polycyclic aromatic hydrocarbons, Anal. Chim. Acta 934 (2016) 106-113.

[31] Y. Wang, Y. Sun, B. Xu, X. Li, X. Wang, H. Zhang, D. Song, Matrix solid-phase dispersion coupled with magnetic ionic liquid dispersive liquid-liquid microextraction for the determination of triazine herbicides in oilseeds, Anal. Chim. Acta 888 (2015) 67-74.

[32] A. Stefansson, Iron(III) hydrolysis and solubility at $25^{\circ} \mathrm{C}$, Environ. Sci. Technol. 41 (2007) 6117-6123.

[33] M. Döbbelin, V. Jovanovski, I. Llarena, L.J. Claros Marfil, G. Cabañero, J. Rodriguez, D. Mecerreyes, Synthesis of paramagnetic polymers using ionic liquid chemistry, Polym. Chem. 2 (2011) $1275-1278$. 
[34] S. Hayashi, S. Saha, H. Hamaguchi, A new class of magnetic fluids: bmim[FeCl 4$]$ and nbmim $\left[\mathrm{FeCl}_{4}\right]$ ionic liquids, IEEE Trans. Magn. 42 (2006) 12-14.

[35] K.D. Clark, M.M. Yamsek, O. Nacham, J.L. Anderson, Magnetic ionic liquids as PCRcompatible solvents for DNA extraction from biological samples, Chem. Commun. 51 (2015) 16771-16773.

[36] E. Santos, J. Albo, A. Rosatella, C.A.M. Afonso, Á. Irabien, Synthesis and characterization of magnetic ionic liquids (MILs) for $\mathrm{CO}_{2}$ separation, J. Chem. Technol. Biotechnol. 89 (2014) $866-871$.

[37] R.E. Del Sesto, T.M. McCleskey, A.K. Burrell, G.A. Baker, J.D. Thompson, B.L. Scott, J.S. Wilkes, P. Williams, Structure and magnetic behavior of transition metal based ionic liquids, Chem. Commun. (2008) 447-449.

[38] M. Yang, X. Wu, Y. Jia, X. Xi, X. Yang, R. Lu, S. Zhang, H. Gao, W. Zhou, Use of magnetic effervescent tablet-assisted ionic liquid dispersive liquid-liquid microextraction to extract fungicides from environmental waters with the aid of experimental design methodology, Anal. Chim. Acta 906 (2016) 118-127.

[39] B. Wielgomas, W. Czarnowski, Headspace single-drop microextraction and GC-ECD determination of chlorpyrifos-ethyl in rat liver, Anal. Bioanal. Chem. 390 (2008) 1933-1941.

[40] A. Steffen, J. Pawliszyn, Analysis of flavor volatiles using headspace solid-phase microextraction, J. Agric. Food Chem. 44 (1996) 2187-2193.

[41] P.N. Carvalho, P.N. Rodrigues, F. Alves, R. Evangelista, M.C. Basto, M.T. Vasconcelos, An expeditious method for the determination of organochlorine pesticides residues in estuarine sediments using microwave assisted pre-extraction and automated headspace solid-phase 
microextraction coupled to gas chromatography-mass spectrometry, Talanta 76 (2008) 11241129.

[42] D.W. Lachenmeier, U. Nerlich, T. Kuballa, Automated determination of ethyl carbamate in stone-fruit spirits using headspace solid-phase microextraction and gas chromatography-tandem mass spectrometry, J. Chromatogr. A 1108 (2006) 116-120.

[43] L. Wolska, M. Rawa-Adkonis, J. Namiesnik, Determining PAHs and PCBs in aqueous samples: finding and evaluating sources of error, Anal. Bioanal. Chem. 382 (2005) 1389-1397.

[44] P. Liang, J. Xu, Q. Li, Application of dispersive liquid-liquid microextraction and highperformance liquid chromatography for the determination of three phthalate esters in water samples, Anal. Chim. Acta 609 (2008) 53-58.

[45] A. Daneshfar, T. Khezeli, H.J. Lotfi, Determination of cholesterol in food samples using dispersive liquid-liquid microextraction followed by HPLC-UV, J. Chromatogr. B 877 (2009) $456-460$.

[46] J. Pawliszyn, Theory of solid-phase microextraction, J. Chromatogr. Sci. 38 (2000) 270-278. [47] C.L. Ye, Q.X. Zhou, X.M. Wang, Headspace liquid-phase microextraction using ionic liquid as extractant for the preconcentration of dichlorodiphenyltrichloroethane and its metabolites at trace levels in water samples, Anal. Chim. Acta 572 (2006) 165-171.

[48] A. Tankeviciute, R. Kazlauskas, V. Vickackaite, Headspace extraction of alcohols into a single drop, Analyst 126 (2001) 1674-1677.

[49] T. Gorecki, J. Pawliszyn, Effect of sample volume on quantitative analysis by solid-phase microextraction, Analyst 122 (1997) 1079-1086. 


\section{Figure Legends}

Figure 1. Sorption-time profiles for the DLLME method using the $\left[\mathrm{P}_{6,6,6,14^{+}}\right]_{2}\left[\mathrm{MnCl}_{4}{ }^{2-}\right] \mathrm{MIL}$. (A) (•) Acetophenone; (X) 2-Chloroaniline; (-) $\alpha, \alpha, \alpha$-6-tetrafluoro-m-toluidine; ( $\diamond)$ 1-Chloro-4nitrobenzene; (B) ( $\boldsymbol{\Delta}$ ) 2-Bromo-4-fluorobenzaldehyde; (•) Biphenyl; ( $\square$ ) 4Chlorobutyrophenone; (ם) 2-Nitronaphthalene. (C) (open triangle) Benzophenone; (+) Fluorene; (*) Phenanthrene; (०) Anthracene. Concentration of $\alpha, \alpha, \alpha$-6-tetrafluoro-m-toluidine: $300 \mu \mathrm{g} \mathrm{L}^{-1}$, concentration of biphenyl: $120 \mu \mathrm{g} \mathrm{L}^{-1}$, concentration of all other analytes: $600 \mu \mathrm{g} \mathrm{L}^{-1}$; Disperser solvent: acetonitrile; MIL mass: $20 \mathrm{mg}$; Disperser solvent volume: $5 \mu \mathrm{L}$; $\mathrm{NaCl}$ concentration in the aqueous solution: $0 \%(\mathrm{w} / \mathrm{v})$.

Figure 2. Comparison of disperser solvent volumes for DLLME method using the $\left[\mathrm{P}_{6,6,6,14}{ }^{+}\right]_{2}\left[\mathrm{MnCl}_{4}{ }^{2-}\right]$ MIL. $5 \mu \mathrm{L}$ (black bar); $10 \mu \mathrm{L}$ (gray bar); $15 \mu \mathrm{L}$ (open bar); $20 \mu \mathrm{L}$ (dashed bar). Concentration of $\alpha, \alpha, \alpha$-6-tetrafluoro-m-toluidine: $300 \mu \mathrm{g} \mathrm{L}^{-1}$, concentration of biphenyl: $120 \mu \mathrm{g} \mathrm{L}^{-1}$, concentration of all other analytes: $600 \mu \mathrm{g} \mathrm{L}^{-1}$; Disperser solvent: acetonitrile; MIL mass: $20 \mathrm{mg}$; Extraction time: $120 \mathrm{~s}$; $\mathrm{NaCl}$ concentration in the aqueous solution: $0 \%(\mathrm{w} / \mathrm{v})$.

Figure 3. Comparison of disperser solvent volumes for the DLLME method using [Aliquat $\left.{ }^{+}\right]_{2}\left[\mathrm{MnCl}_{4}{ }^{2-}\right]$ MIL. $5 \mu \mathrm{L}$ (black bar); $10 \mu \mathrm{L}$ (gray bar); $15 \mu \mathrm{L}$ (open bar); $20 \mu \mathrm{L}$ (dashed bar). Concentration of $\alpha, \alpha, \alpha-6$-tetrafluoro-m-toluidine: $300 \mu \mathrm{g} \mathrm{L}^{-1}$, concentration of biphenyl: $120 \mu \mathrm{g} \mathrm{L}^{-1}$, concentration of all other analytes: $600 \mu \mathrm{g} \mathrm{L}^{-1}$; Disperser solvent: methanol; MIL mass: $20 \mathrm{mg}$; Extraction time: $60 \mathrm{~s} ; \mathrm{NaCl}$ concentration in the aqueous solution: $30 \%(\mathrm{w} / \mathrm{v}$ ).

Figure 4. Sorption-time profiles for the DLLME method using [Aliquat $\left.{ }^{+}\right]_{2}\left[\mathrm{MnCl}_{4}{ }^{2-}\right] \mathrm{MIL}$. (A) (•) Acetophenone; (X) 2-chloroaniline; (-) $\alpha, \alpha, \alpha$-6-tetrafluoro-m-toluidine; $(\diamond)$ 1-Chloro-4nitrobenzene; (B) ( $\boldsymbol{\Delta}$ ) 2-Bromo-4-fluorobenzaldehyde; (•) Biphenyl; ( $\square$ ) 4Chlorobutyrophenone; (open triangle) Benzophenone; (+) Fluorene. (C) (ם) 2-Nitronaphthalene; (*) Phenanthrene; (०) Anthracene. Concentration of $\alpha, \alpha, \alpha$-6-tetrafluoro-m-toluidine: $300 \mu \mathrm{g} \mathrm{L}^{-1}$, concentration of biphenyl: $120 \mu \mathrm{g} \mathrm{L}^{-1}$, concentration of all other analytes: $600 \mu \mathrm{g} \mathrm{L}^{-1}$; Disperser solvent: methanol; MIL mass: $20 \mathrm{mg}$; Disperser solvent volume: $5 \mu \mathrm{L}$; $\mathrm{NaCl}$ concentration in the aqueous solution: $30 \%(\mathrm{w} / \mathrm{v})$.

Figure 5. Effect of temperature on extraction efficiencies for the HS-SDME method using (A) $\left[\mathrm{P}_{6,6,6,14}{ }^{+}\right]_{2}\left[\mathrm{MnCl}_{4}{ }^{2-}\right] \mathrm{MIL}$ and (B) $\left[\text { Aliquat }^{+}\right]_{2}\left[\mathrm{MnCl}_{4}{ }^{2-}\right] \mathrm{MIL} .20^{\circ} \mathrm{C}$ (black bar); $40^{\circ} \mathrm{C}$ (gray bar); $60^{\circ} \mathrm{C}$ (open bar). Concentration of $\alpha, \alpha, \alpha-6$-tetrafluoro-m-toluidine: $300 \mu \mathrm{g} \mathrm{L}^{-1}$, concentration of biphenyl: $120 \mu \mathrm{g} \mathrm{L}^{-1}$, concentration of all other analytes: $600 \mu \mathrm{g} \mathrm{L}^{-1}$; $\mathrm{NaCl}$ concentration in the aqueous solution: $30 \%(\mathrm{w} / \mathrm{v})$; Extraction time: $30 \mathrm{~min}$; MIL mass: $10 \mathrm{mg}$; stir rate: $800 \mathrm{rpm}$; headspace volume: $2.5 \mathrm{~mL}$.

Figure 6. Sorption-time profiles for the HS-SDME method using the (A and B) $\left[\mathrm{P}_{6,6,6,14}{ }^{+}\right]_{2}\left[\mathrm{MnCl}_{4}{ }^{2-}\right] \mathrm{MIL}$ and the (C and D) [Aliquat $\left.{ }^{+}\right]_{2}\left[\mathrm{MnCl}_{4}{ }^{2-}\right] \mathrm{MIL}$. (•) Acetophenone; (X) 2chloroaniline; (-) $\alpha, \alpha, \alpha$-6-tetrafluoro-m-toluidine; ( $\Delta$ ) 2-bromo-4-fluorobenzaldehyde; ( $\diamond)$ 1chloro-4-nitrobenzene; ( $\square$ ) 4-chlorobutyrophenone. (open triangle) benzophenone; (ם) 2- 
nitronaphthalene; $(\bullet)$ biphenyl; (+) Fluorene; (*) Phenanthrene; ( $)$ Anthracene. Concentration of $\alpha, \alpha, \alpha$-6-tetrafluoro-m-toluidine: $300 \mu \mathrm{g} \mathrm{L}^{-1}$, concentration of biphenyl: $120 \mu \mathrm{g} \mathrm{L}^{-1}$, concentration of all other analytes: $600 \mu \mathrm{g} \mathrm{L}^{-1}$; $\mathrm{NaCl}$ concentration in the aqueous solution: $30 \%$ (w/v); Temperature: $60^{\circ} \mathrm{C}\left(\left[\mathrm{P}_{6,6,6,14}{ }^{+}\right]_{2}\left[\mathrm{MnCl}_{4}{ }^{2-}\right]\right), 40^{\circ} \mathrm{C}\left(\left[\text { Aliquat }{ }^{+}\right]_{2}\left[\mathrm{MnCl}_{4}{ }^{2-}\right]\right)$; MIL mass: $20 \mathrm{mg}$; stir rate: $800 \mathrm{rpm}$; headspace volume: $2.5 \mathrm{~mL}$. 


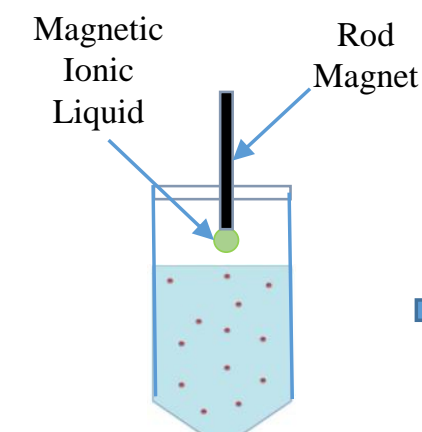

Headspace extraction

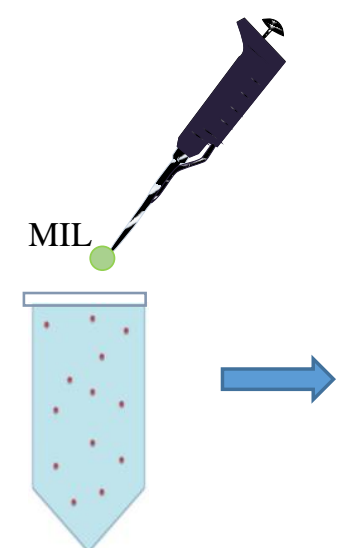

Addition of MIL and organic solvent
Headspace Single Drop Microextraction

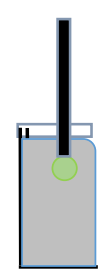

Dissolution of MIL in organic solvent

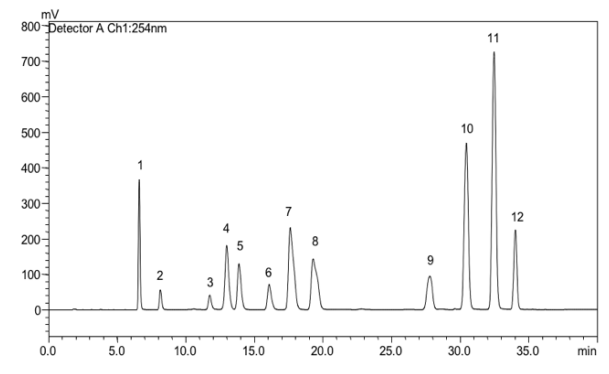

HPLC Separation

\section{Dispersive Liquid-Liquid Microextraction}
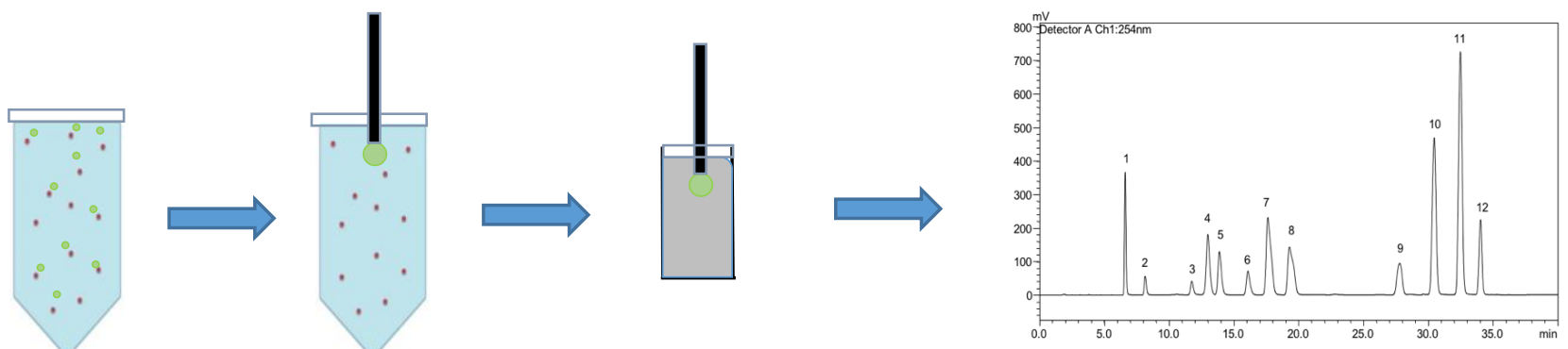

Collection of MIL with

Dissolution of

rod magnet in organic

HPLC Separation

Vortex

$$
\text { solvent }
$$


Table 1. Figures of merit for the extraction of twelve analytes by DLLME using the $\left[\mathrm{P}_{6,6,6,14}{ }^{+}\right]_{2}\left[\mathrm{MnCl}_{4}{ }^{2-}\right] \mathrm{MIL}$ as extraction solvent ${ }^{\mathrm{a}}$.

\begin{tabular}{|c|c|c|c|c|c|c|c|c|}
\hline & \multirow{2}{*}{$\begin{array}{l}\text { Linear } \\
\text { Range } \\
\left(\mu \mathrm{g} \mathrm{L}^{-1}\right)\end{array}$} & \multirow{2}{*}{$\mathrm{R}^{2}$} & \multirow{2}{*}{ Slope \pm SD } & \multirow{2}{*}{$\mathrm{s}_{\mathrm{xy}}^{\mathrm{b}}$} & \multirow{2}{*}{$\begin{array}{c}\text { LOD } \\
\left(\mu \mathrm{g} \mathrm{L}^{-1}\right)\end{array}$} & \multicolumn{3}{|c|}{$\% \operatorname{RSD}(\mathrm{n}=3)$} \\
\hline & & & & & & $5 \mu g \mathrm{~L}^{-1}$ & $20 \mu \mathrm{g} \mathrm{L}^{-1}$ & $300 \mu \mathrm{g} \mathrm{L}{ }^{-1}$ \\
\hline Acetophenone & $1-600$ & 0.998 & $2.734 \pm 0.042$ & 24.5 & 0.5 & 11.7 & 13.0 & 5.8 \\
\hline 2-Chloroaniline & $0.5-300$ & 0.997 & $0.751 \pm 0.014$ & 4.4 & 0.05 & 12.0 & 13.2 & 1.2 \\
\hline $\begin{array}{l}\alpha, \alpha, \alpha \text {-6-Tetrafluoro- } \\
\text { m-toluidine }\end{array}$ & $1-300$ & 0.999 & $0.565 \pm 0.005$ & 1.3 & 1.0 & $13.8^{\mathrm{c}}$ & $0.9^{\mathrm{c}}$ & $4.9^{\mathrm{c}}$ \\
\hline $\begin{array}{l}\text { 2-Bromo-4- } \\
\text { fluorobenzaldehyde }\end{array}$ & $2-600$ & 0.998 & $1.966 \pm 0.035$ & 20.1 & 1.0 & 3.7 & 14.2 & 4.4 \\
\hline 1-Chloro-4-nitrobenzene & $1-600$ & 0.998 & $1.416 \pm 0.022$ & 12.5 & 0.5 & 0.3 & 6.4 & 0.7 \\
\hline 4-Chlorobutyrophenone & $1-600$ & 0.999 & $1.574 \pm 0.011$ & 6.6 & 0.1 & 13.7 & 17.4 & 2.2 \\
\hline Benzophenone & $1-600$ & 0.999 & $5.203 \pm 0.045$ & 26.1 & 0.5 & 5.3 & 5.8 & 3.5 \\
\hline 2-Nitronaphthalene & $2-600$ & 0.997 & $4.462 \pm 0.087$ & 48.7 & 0.2 & 0.9 & 5.4 & 3.1 \\
\hline Biphenyl & $0.2-120$ & 0.999 & $5.569 \pm 0.051$ & 5.9 & 0.1 & $15.0^{\mathrm{d}}$ & $5.3^{\mathrm{d}}$ & $7.1^{\mathrm{d}}$ \\
\hline Fluorene & $0.5-600$ & 0.999 & $6.030 \pm 0.065$ & 38.2 & 0.5 & 3.8 & 5.1 & 3.9 \\
\hline Phenanthrene & $1-600$ & 0.999 & $17.249 \pm 0.14$ & 79.9 & 0.1 & 1.2 & 6.9 & 3.8 \\
\hline Anthracene & $0.5-600$ & 0.998 & $25.873 \pm 0.43$ & 250.5 & 0.1 & 9.0 & 8.6 & 2.0 \\
\hline
\end{tabular}

${ }^{a}$ Conditions: disperser solvent, acetonitrile; MIL mass, $20 \mathrm{mg}$; extraction time, $120 \mathrm{~s}$; disperser solvent volume, $20 \mu \mathrm{L}$; $\mathrm{NaCl}$ concentration in aqueous solution, $30 \%(\mathrm{w} / \mathrm{v})$.

${ }^{\mathrm{b}}$ Standard deviation of regression.

${ }^{\mathrm{c}}$ Precision at 2.5, 10, and $150 \mu \mathrm{g} \mathrm{\textrm {L } ^ { - 1 }}$.

${ }^{\mathrm{d}}$ Precision at 1,4 , and $120 \mu \mathrm{g} \mathrm{L}{ }^{-1}$. 
Table 2. Figures of merit for the extraction of twelve analytes by SDME using the $\left[\mathrm{P}_{6,6,6,14}{ }^{+}\right]_{2}\left[\mathrm{MnCl}_{4}{ }^{2-}\right] \mathrm{MIL}$ as extraction solvent ${ }^{\mathrm{a}}$.

\begin{tabular}{|c|c|c|c|c|c|c|c|c|}
\hline \multirow{2}{*}{ Analyte } & \multirow{2}{*}{$\begin{array}{l}\text { Linear } \\
\text { Range } \\
\left(\mu \mathrm{g} \mathrm{L}^{-1}\right)\end{array}$} & \multirow{2}{*}{$\mathrm{R}^{2}$} & \multirow{2}{*}{ Slope \pm SD } & \multirow{2}{*}{$\mathrm{S}_{\mathrm{yx}}^{\mathrm{b}}$} & \multirow{2}{*}{$\begin{array}{c}\mathrm{LOD} \\
\left(\mu \mathrm{g} \mathrm{L}^{-1}\right)\end{array}$} & \multicolumn{3}{|c|}{$\% \operatorname{RSD}(\mathrm{n}=3)$} \\
\hline & & & & & & $5 \mu \mathrm{g} \mathrm{L}^{-1}$ & $20 \mu \mathrm{g} \mathrm{L}^{-1}$ & $300 \mu \mathrm{g} \mathrm{L}^{-1}$ \\
\hline Acetophenone & $1-300$ & 0.999 & $3127.4 \pm 26.4$ & 8704.1 & 1.0 & 13.3 & 7.0 & 2.3 \\
\hline 2-Chloroaniline & $1-300$ & 0.999 & $786.5 \pm 10.5$ & 3164.4 & 0.2 & 7.6 & 6.0 & 2.6 \\
\hline $\begin{array}{l}\alpha, \alpha, \alpha \text {-6-Tetrafluoro- } \\
\text { m-toluidine }\end{array}$ & $1-300$ & 0.996 & $2282.5 \pm 56.5$ & 15920.2 & 0.5 & $10.2^{\mathrm{c}}$ & $12.2^{\mathrm{c}}$ & $3.1^{\mathrm{c}}$ \\
\hline $\begin{array}{l}\text { 2-Bromo-4- } \\
\text { fluorobenzaldehyde }\end{array}$ & $0.5-300$ & 0.996 & $3396.1 \pm 73.7$ & 22763.7 & 0.5 & 8.2 & 8.0 & 0.9 \\
\hline 1-Chloro-4-nitrobenzene & $1-300$ & 0.999 & $2427.6 \pm 24.9$ & 7179.6 & 0.2 & 9.0 & 7.6 & 2.4 \\
\hline 4-Chlorobutyrophenone & $2-300$ & 0.998 & $1295.2 \pm 24.5$ & 7062.0 & 0.2 & 5.4 & 5.9 & 5.1 \\
\hline Benzophenone & $2-300$ & 0.997 & $5189.9 \pm 115.8$ & 33444.7 & 1.0 & 11.4 & 1.5 & 7.1 \\
\hline 2-Nitronaphthalene & $2-300$ & 0.994 & $4085.1 \pm 134.8$ & 38943.0 & 1.0 & 4.2 & 2.2 & 9.0 \\
\hline Biphenyl & $0.1-60$ & 0.998 & $21987.8 \pm 353.2$ & 4565.5 & 0.04 & $13.8^{\mathrm{d}}$ & $5.9^{\mathrm{d}}$ & $4.9^{\mathrm{d}}$ \\
\hline Fluorene & $0.2-300$ & 0.994 & $11552.5 \pm 330.1$ & 99015.1 & 0.2 & 1.8 & 9.5 & 2.2 \\
\hline Phenanthrene & $1-600$ & 0.998 & $23467.6 \pm 391.0$ & 231577.4 & 0.2 & 15.1 & 5.1 & 5.2 \\
\hline Anthracene & $1-300$ & 0.999 & $10109.0 \pm 126.2$ & 37866.9 & 0.5 & 3.5 & 8.9 & 2.7 \\
\hline
\end{tabular}

${ }^{\text {a }}$ Conditions: temperature: $60^{\circ} \mathrm{C}$; MIL mass, $20 \mathrm{mg}$; extraction time, $60 \mathrm{~min}$; stir rate: $400 \mathrm{rpm}$;

$\mathrm{NaCl}$ concentration in aqueous solution, $30 \%$ (w/v).

${ }^{\mathrm{b}}$ Standard deviation of regression.

${ }^{\mathrm{c}}$ Precision at $2.5,10$, and $150 \mu \mathrm{g} \mathrm{\textrm {L } ^ { - 1 }}$.

${ }^{\mathrm{d}}$ Precision at 1,4 , and $120 \mu \mathrm{g} \mathrm{L} \mathrm{L}^{-1}$. 
Table 3. Enrichment factors of the target analytes using the $\left[\mathrm{P}_{6,6,6,14}{ }^{+}\right]_{2}\left[\mathrm{MnCl}_{4}{ }^{2-}\right] \mathrm{MIL}$ and the $\left[\text { Aliquat }{ }^{+}\right]_{2}\left[\mathrm{MnCl}_{4}{ }^{2-}\right] \mathrm{MIL}$ in the DLLME and the SDME methods.

\begin{tabular}{lcc|cc}
\hline \multirow{2}{*}{\multicolumn{1}{c}{ Analyte }} & \multicolumn{4}{c}{ Enrichment Factor ${ }^{\mathrm{a}}$} \\
\cline { 2 - 5 } & \multicolumn{2}{c}{ DLLME } & \multicolumn{2}{c}{ SDME } \\
\cline { 2 - 5 } & $\begin{array}{c}{\left[\mathrm{P}_{6,6,6,14^{+}}\right]_{2}} \\
{\left[\mathrm{MnCl}_{4}{ }^{--}\right]}\end{array}$ & $\begin{array}{c}{\left[\mathrm{Aliquat}^{+}\right]_{2}} \\
{\left[\mathrm{MnCl}_{4}{ }^{2-}\right]}\end{array}$ & $\begin{array}{c}{\left[\mathrm{P}_{6,6,6,14}{ }^{+}\right]_{2}} \\
{\left[\mathrm{MnCl}_{4}{ }^{2-}\right]}\end{array}$ & $\begin{array}{c}{\left[\mathrm{Aliquat}^{+}\right]_{2}} \\
{\left[\mathrm{MnCl}_{4}{ }^{-2}\right]}\end{array}$ \\
\hline Acetophenone & 29.4 & 4.2 & 25.3 & 18.4 \\
\hline 2-Chloroaniline & 87.0 & 19.0 & 17.0 & 10.4 \\
\hline$\alpha, \alpha, \alpha-6-T e t r a f l u o r o-m-t o l u i d i n e$ & 36.7 & 19.1 & 72.7 & 71.1 \\
\hline 2-Bromo-4-fluorobenzaldehyde & 36.3 & 10.0 & 46.0 & 42.4 \\
\hline 1-Chloro-4-nitrobenzene & 36.8 & 14.8 & 45.8 & 38.6 \\
\hline 4-Chlorobutyrophenone & 38.1 & 20.4 & 24.9 & 14.1 \\
\hline Benzophenone & 41.2 & 27.5 & 32.4 & 19.5 \\
\hline 2-Nitronaphthalene & 36.0 & 29.2 & 29.1 & 16.1 \\
\hline Biphenyl & 46.4 & 29.8 & 82.1 & 78.2 \\
\hline Fluorene & 44.6 & 31.5 & 58.0 & 24.1 \\
\hline Phenanthrene & 55.6 & 31.1 & 49.4 & 8.2 \\
\hline Anthracene & 64.3 & 37.2 & 21.8 & 1.7 \\
\hline
\end{tabular}

${ }^{\text {a }}$ Calculated at $30 \mu \mathrm{g} \mathrm{L}{ }^{-1}$ for $\alpha, \alpha, \alpha$-6-tetrafluoro-m-toluidine, $12 \mu \mathrm{g} \mathrm{L}^{-1}$ for biphenyl, and $60 \mu \mathrm{g} \mathrm{L}^{-1}$ for all other analytes. 
Table 4. Relative recoveries of the target analytes from lake water using the $\left[\mathrm{P}_{6,6,6,14}{ }^{+}\right]_{2}\left[\mathrm{MnCl}_{4}{ }^{2-}\right]$ MIL by the optimized DLLME and SDME method.

\begin{tabular}{lcc|cc}
\hline \multirow{2}{*}{\multicolumn{1}{c}{ Analyte }} & \multicolumn{3}{c}{ \% Recovery SD $(\mathrm{n}=3)$} \\
\cline { 2 - 5 } & \multicolumn{2}{c}{ DLLME } & \multicolumn{2}{c}{ SDME } \\
\cline { 2 - 5 } & $20 \mu \mathrm{g} \mathrm{L}^{-1}$ & $100 \mu \mathrm{g} \mathrm{L}^{-1}$ & $20 \mu \mathrm{g} \mathrm{L}^{-1}$ & $100 \mu \mathrm{g} \mathrm{L}^{-1}$ \\
\hline Acetophenone & $104.5 \pm 8.5$ & $77.0 \pm 3.6$ & $76.8 \pm 9.3$ & $70.4 \pm 7.4$ \\
\hline 2-Chloroaniline & $68.7 \pm 13.8$ & $86.3 \pm 3.7$ & $82.0 \pm 7.7$ & $78.1 \pm 7.2$ \\
\hline$\alpha, \alpha, \alpha-6-T e t r a f l u o r o-m-t o l u i d i n \mathrm{a}^{\mathrm{a}}$ & $77.0 \pm 7.1$ & $72.7 \pm 6.7$ & $109.6 \pm 3.6$ & $69.2 \pm 3.6$ \\
\hline 2-Bromo-4-fluorobenzaldehyde & $79.2 \pm 4.3$ & $108.2 \pm 13.2$ & $89.2 \pm 10.7$ & $76.7 \pm 10.8$ \\
\hline 1-Chloro-4-nitrobenzene $^{\text {4-Chlorobutyrophenone }}$ & $85.1 \pm 6.3$ & $85.8 \pm 9.1$ & $88.8 \pm 3.3$ & $66.8 \pm 12.4$ \\
\hline Benzophenone & $82.7 \pm 10.9$ & $77.1 \pm 8.2$ & $74.4 \pm 14.0$ & $85.4 \pm 8.3$ \\
\hline 2-Nitronaphthalene & $71.5 \pm 10.2$ & $101.1 \pm 6.5$ & $83.4 \pm 7.1$ & $93.7 \pm 6.7$ \\
\hline Biphenyl & $91.7 \pm 1.8$ & $91.0 \pm 10.2$ & $93.0 \pm 5.0$ & $109.2 \pm 10.3$ \\
\hline Fluorene & $87.3 \pm 12.2$ & $79.5 \pm 3.1$ & $70.2 \pm 4.3$ & $87.2 \pm 8.5$ \\
\hline Phenanthrene & $101.8 \pm 3.0$ & $89.6 \pm 2.6$ & $72.3 \pm 11.2$ & $105.7 \pm 3.8$ \\
\hline Anthracene & $83.6 \pm 3.8$ & $80.1 \pm 10.8$ & $83.6 \pm 13.6$ & $75.2 \pm 5.3$ \\
\hline
\end{tabular}

${ }^{\mathrm{a}}$ Recovery at 10 and $50 \mu \mathrm{g} \mathrm{L}{ }^{-1}$.

${ }^{\mathrm{b}}$ Recovery at 4 and $20 \mu \mathrm{g} \mathrm{L}{ }^{-1}$. 
Figure 1
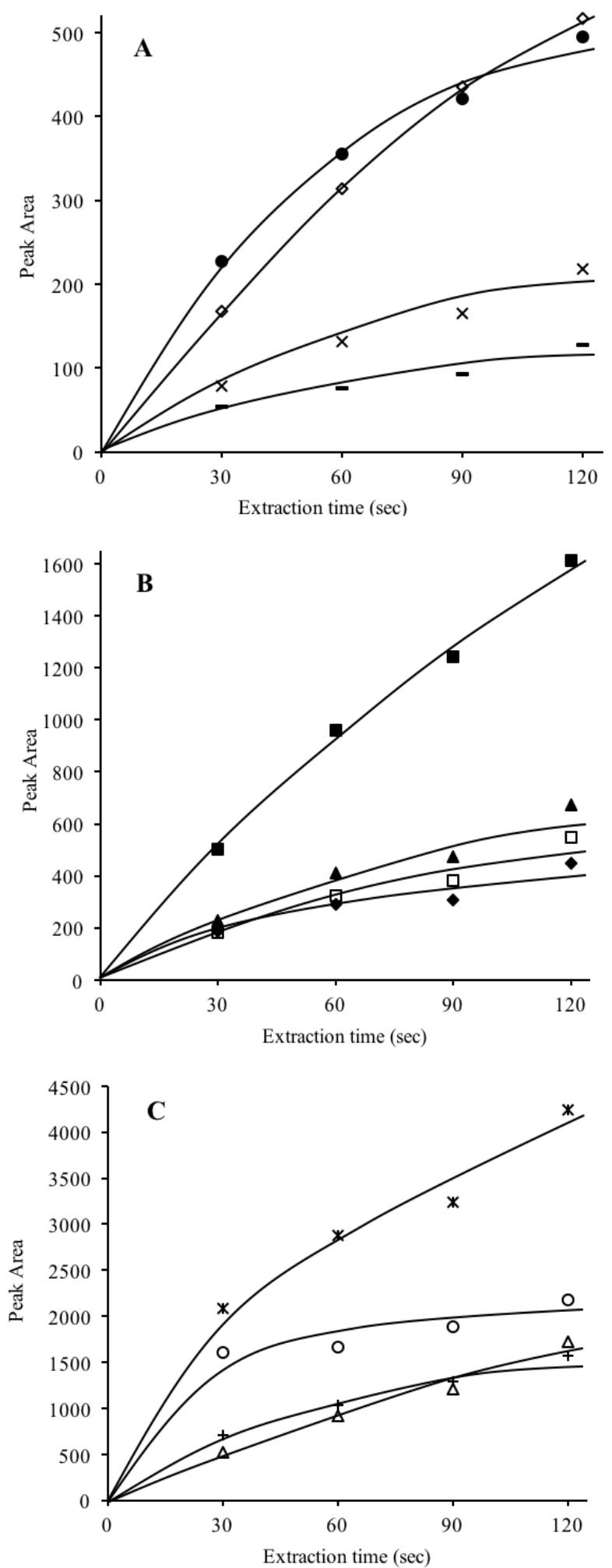
Figure 2

Figure 2

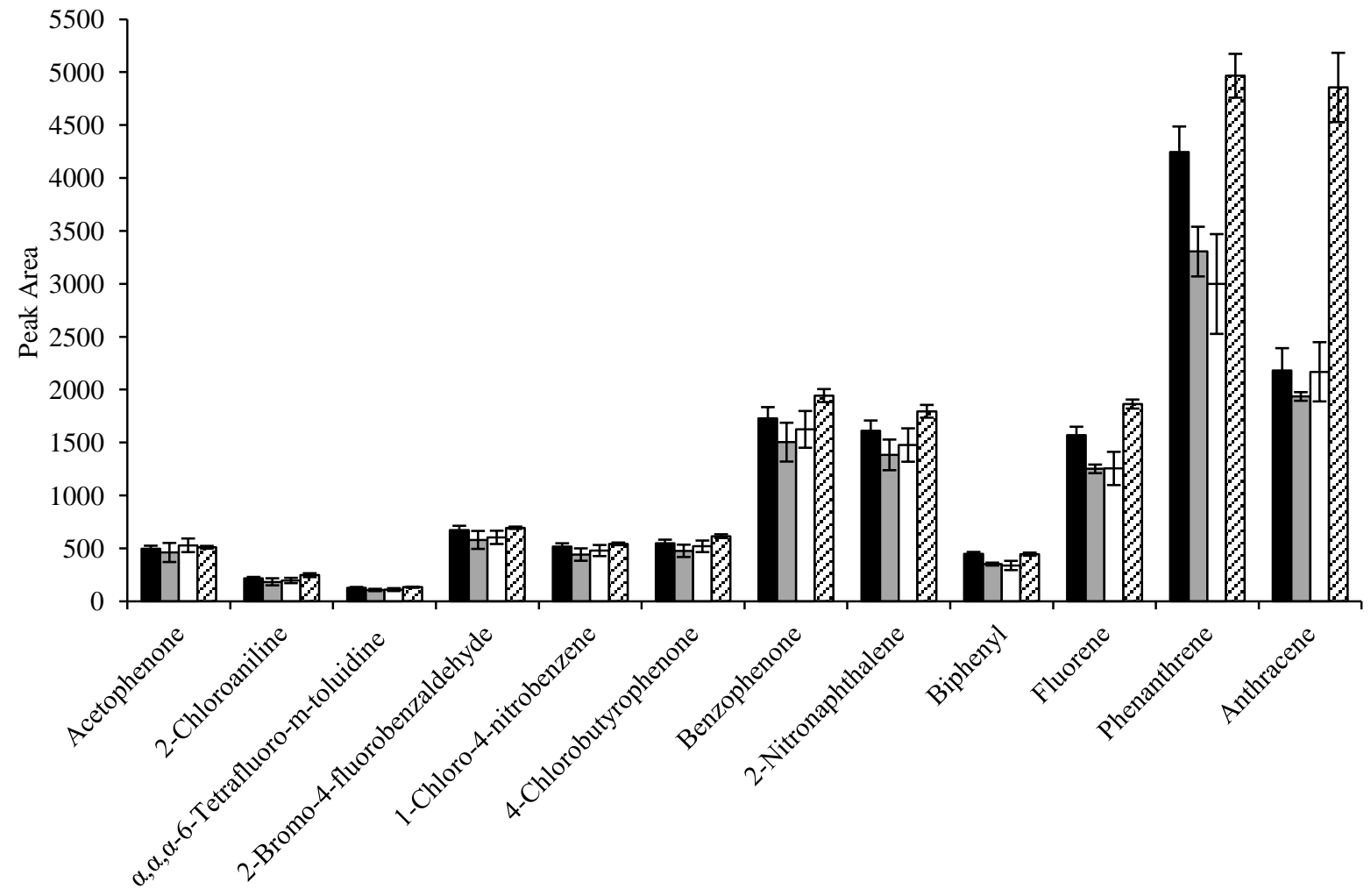


Figure 3

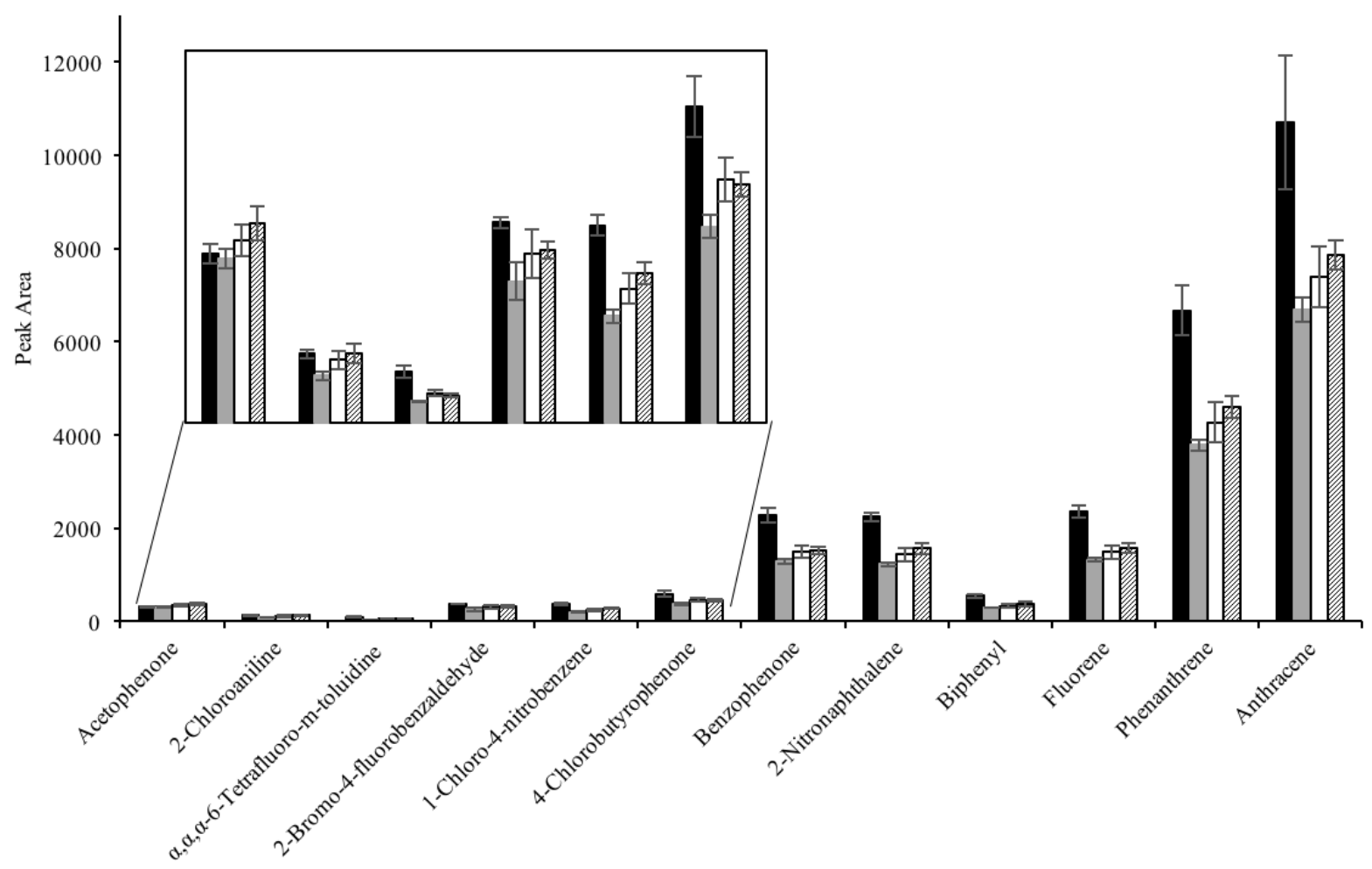


Figure 4
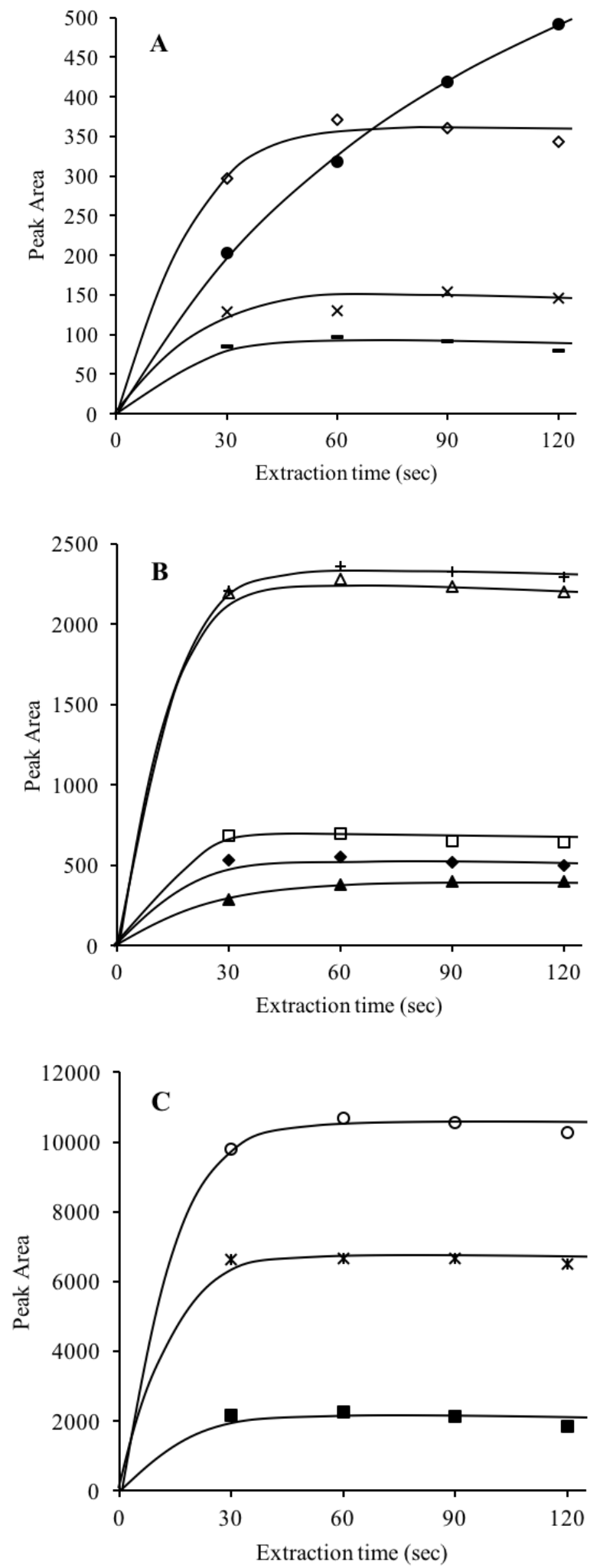
Figure 5

A

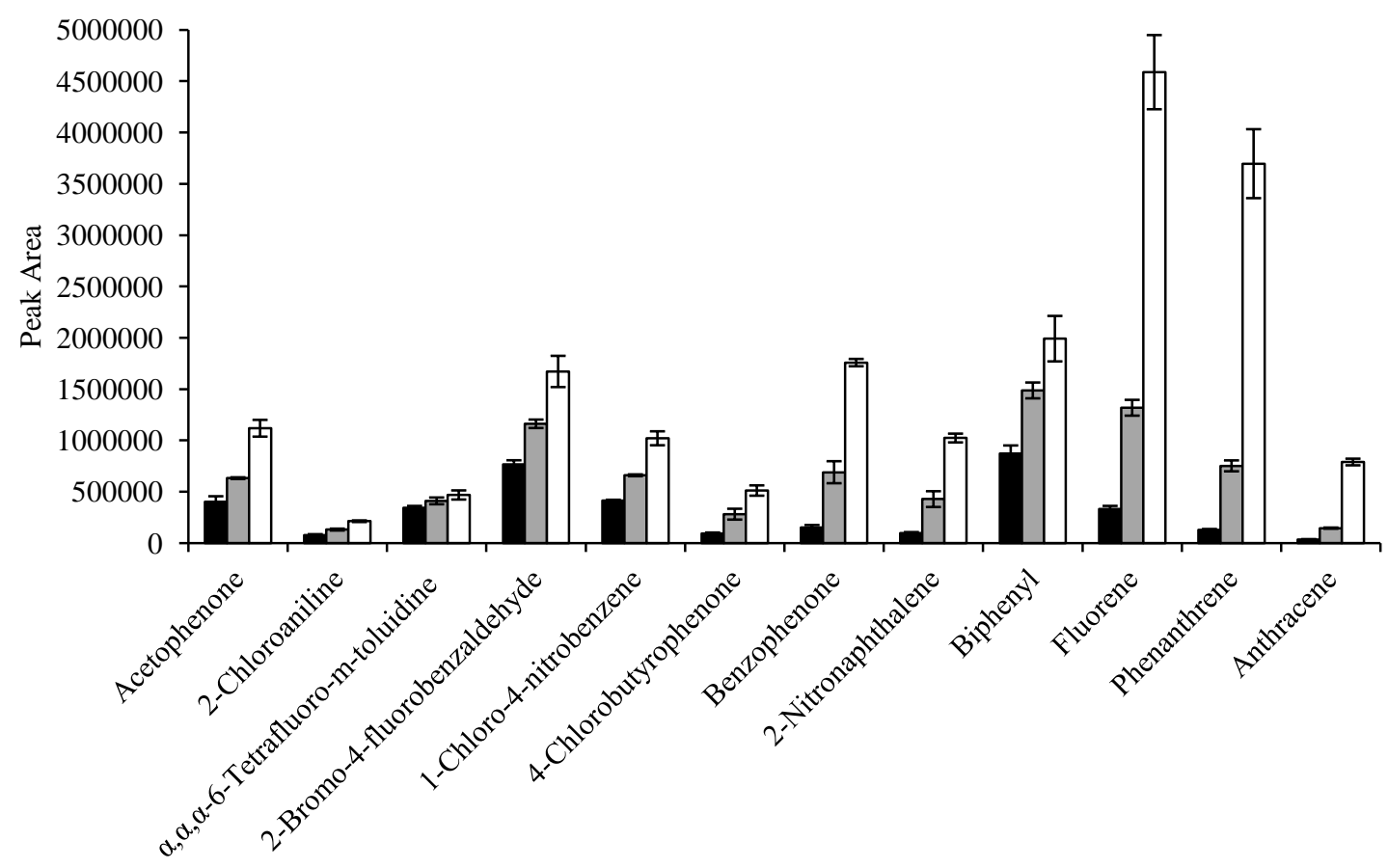

\section{B}

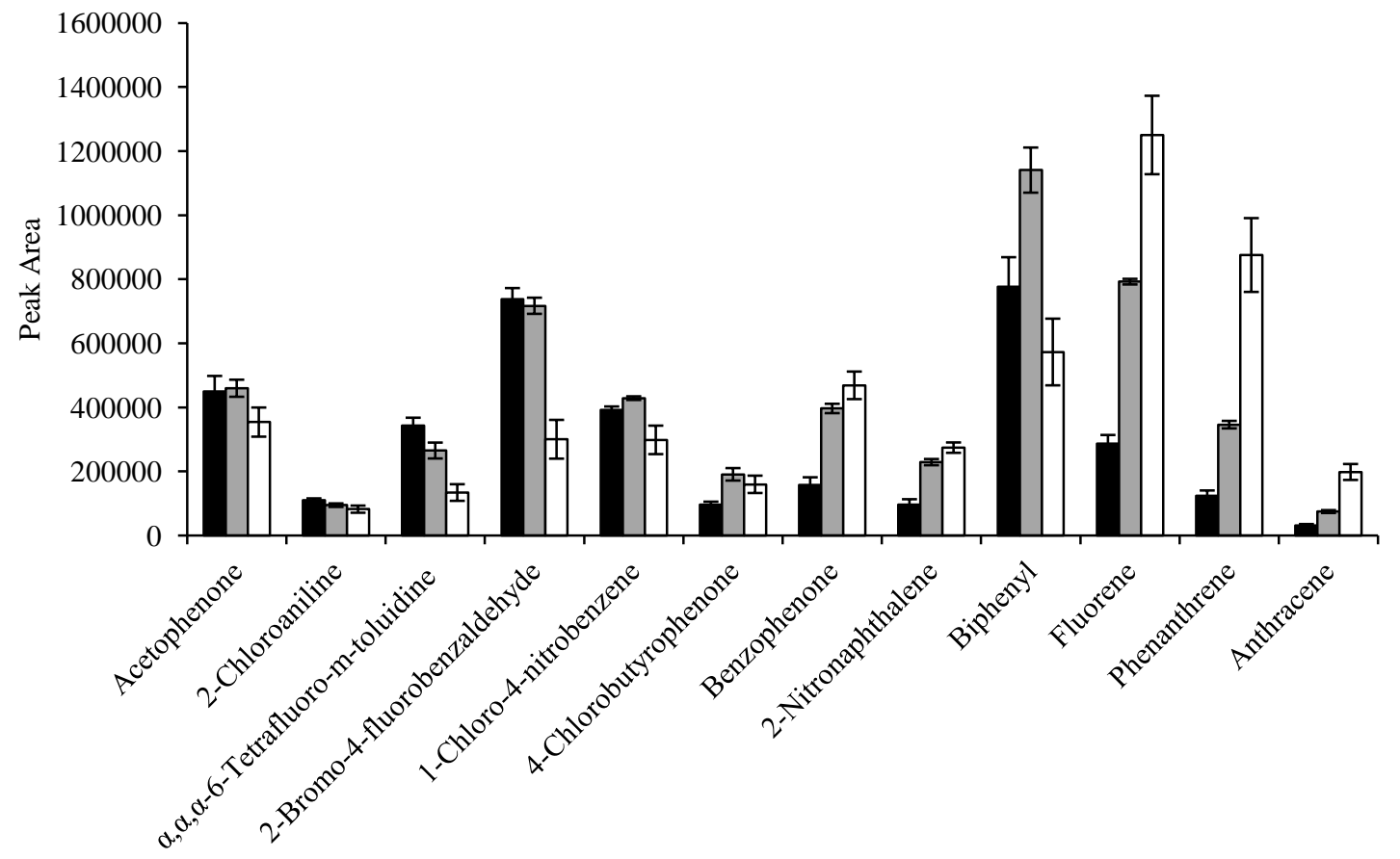


Figure 6
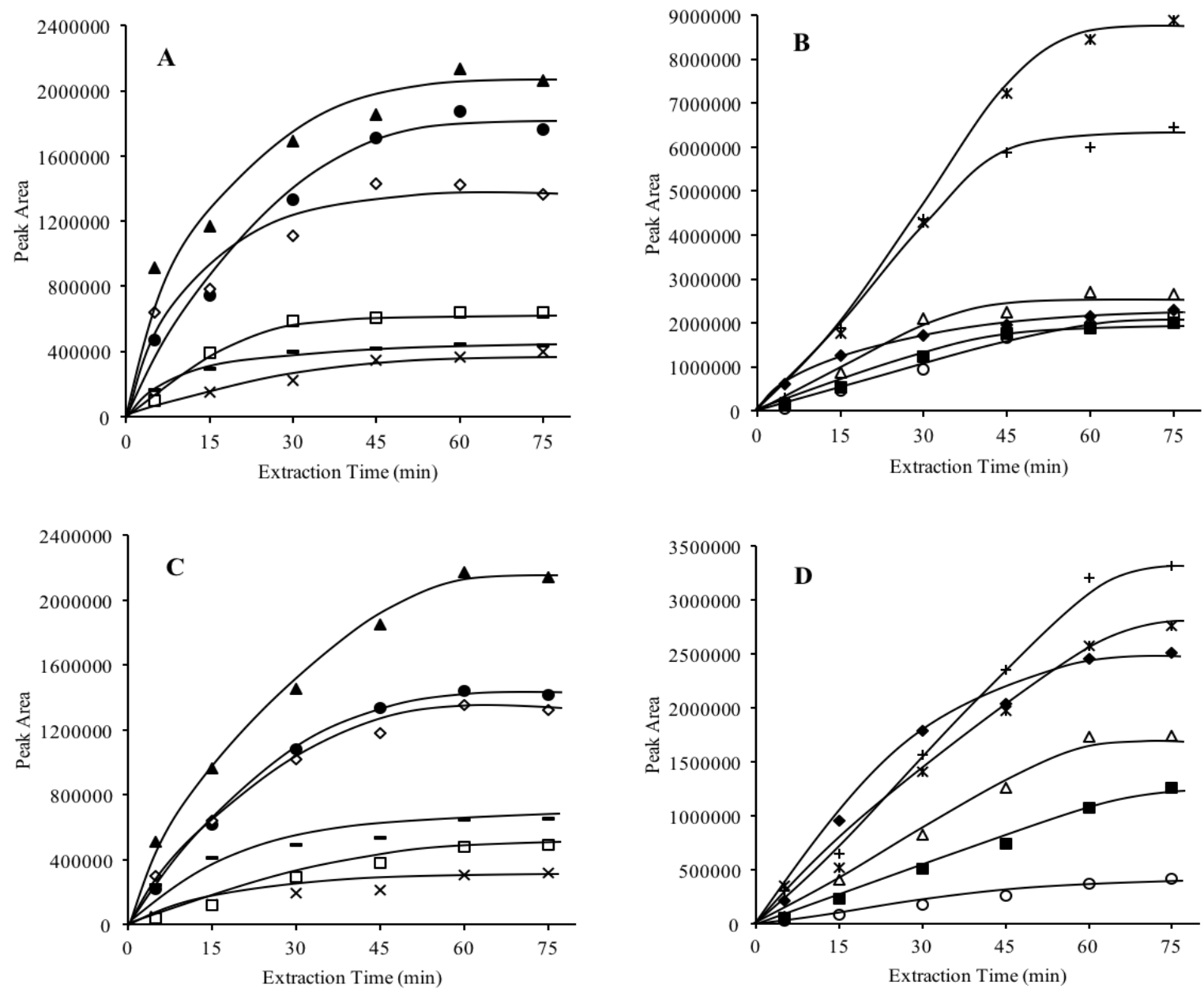